\title{
Small Column Ion Exchange Analysis for Removal of Cesium from SRS Low Curie Salt Solutions Using Crystalline Silicotitanate (CST) Resin
}

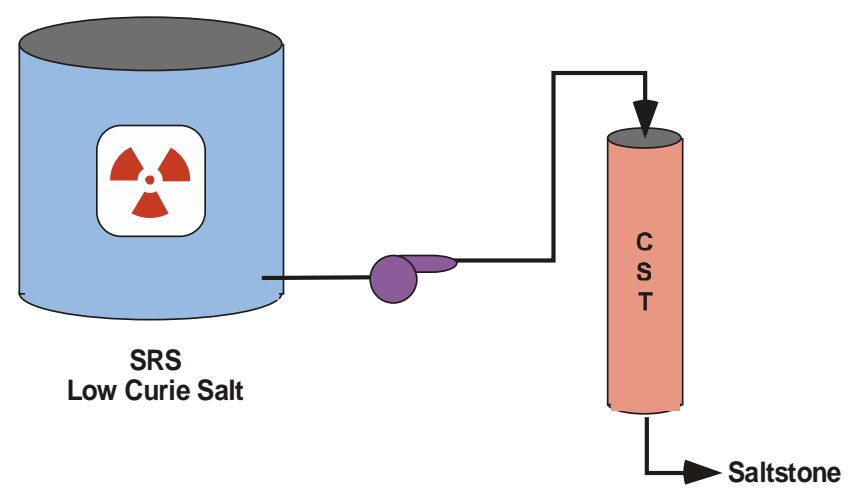

Westinghouse Savannah River Company

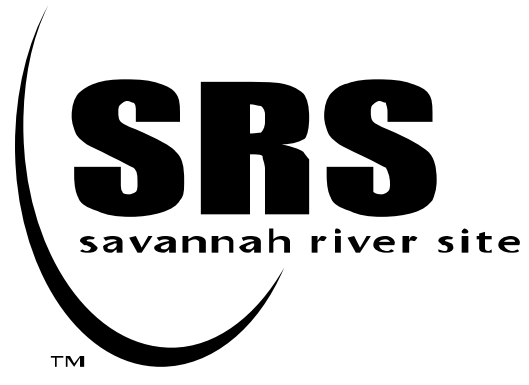

Prepared for the U.S. Department of Energy under Contract No. DE-AC09-96SR18500 
This document was prepared in conjunction with work accomplished under Contract No. DE-AC09-96SR18500 with the U. S. Department of Energy.

\section{DISCLAIMER}

This report was prepared as an account of work sponsored by an agency of the United States Government. Neither the United States Government nor any agency thereof, nor any of their employees, makes any warranty, express or implied, or assumes any legal liability or responsibility for the accuracy, completeness, or usefulness of any information, apparatus, product or process disclosed, or represents that its use would not infringe privately owned rights. Reference herein to any specific commercial product, process or service by trade name, trademark, manufacturer, or otherwise does not necessarily constitute or imply its endorsement, recommendation, or favoring by the United States Government or any agency thereof. The views and opinions of authors expressed herein do not necessarily state or reflect those of the United States Government or any agency thereof.

This report has been reproduced directly from the best available copy.

Available for sale to the public, in paper, from: U.S. Department of Commerce, National Technical Information Service, 5285 Port Royal Road, Springfield, VA 22161, phone: (800) 553-6847, fax: (703) 605-6900

email: orders@ntis.fedworld.gov

online ordering: http://www.ntis.gov/help/index.asp

Available electronically at http://www.osti.gov/bridge

Available for a processing fee to U.S. Department of Energy and its contractors, in paper, from: U.S. Department of Energy, Office of Scientific and Technical Information, P.O. Box 62, Oak Ridge, TN 37831-0062,

phone: (865)576-8401,

fax: (865)576-5728

email: $\underline{\text { reports@ adonis.osti.gov }}$ 
WSRC-TR-2003-00430

Revision 0

KEYWORDS:

Waste Processing Ion Exchange Technology Crystalline Silicotitanate

Cesium ZAM

VERSE-LC

Column Modeling

RETENTION - Permanent

\section{Small Column Ion Exchange Analysis for Removal of Cesium from SRS Low Curie Salt Solutions Using Crystalline Silicotitanate (CST) Resin}

SAVANNAH RIVER TECHNOLOGY CENTER

S. E. Aleman

L. L. Hamm

Publication Date: December 2003

Westinghouse Savannah River Company

Savannah River Site

Aiken, SC 29808

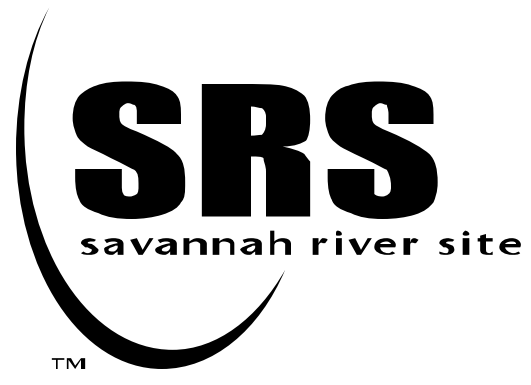

Prepared for the U.S. Department of Energy under Contract No. DE-AC09-96SR18500 
This page was intentionally left blank 


\section{TABLE OF CONTENTS}

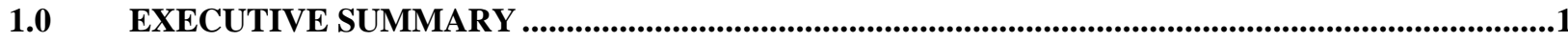

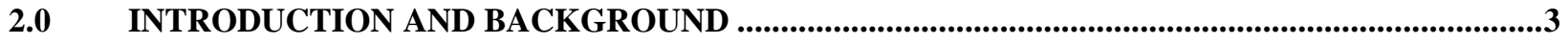

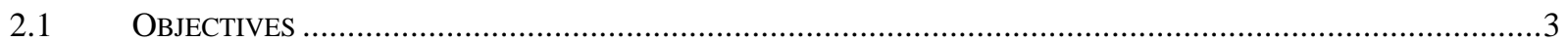

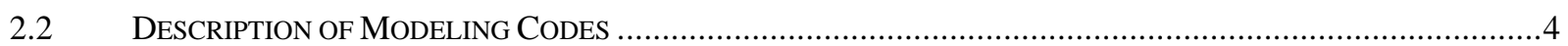

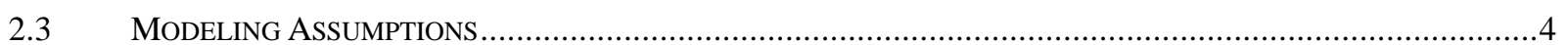

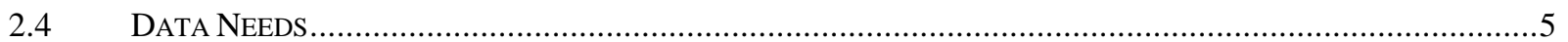

3.0 LCS COLUMN DESIGNS AND PERFORMANCE SCENARIOS .................................................6

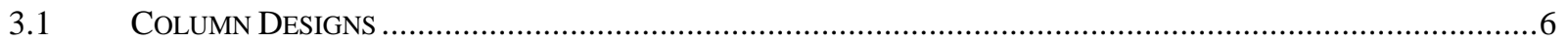

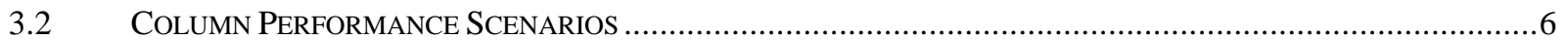

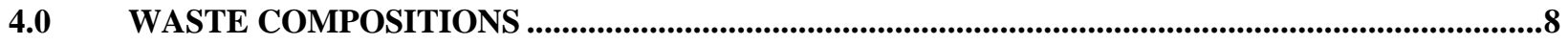

4.1 LCS Middle Composition (Cesium, Potassium and Hydroxide Concentration Variation)...........8

4.2 LCS MIDDLE COMPOSITION (DILUTION AND CONCENTRATION) ...........................................................

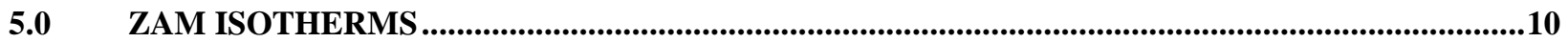

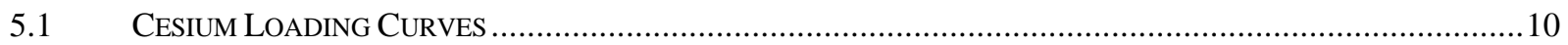

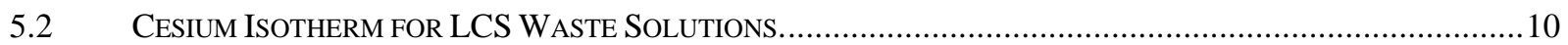

5.3 CESIUM ISOTHERM FOR RECENT TANK 41H DiSSOLVED SALT SOLUTION. ................................................10

5.4 CESIUM ISOTHERM FOR LCS MIDDLE WASTE SOLUTION AT VARIOUS TEMPERATURES. ...........................10

5.5 Cesium ISOTHERM FOR LCS MidDle WASTE SOLUTION AT VARIOUS POTASSIUM CONCENTRATIONS. .....14

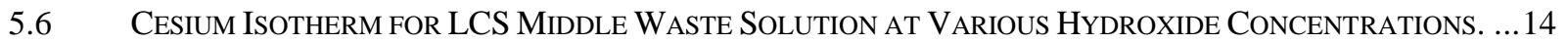

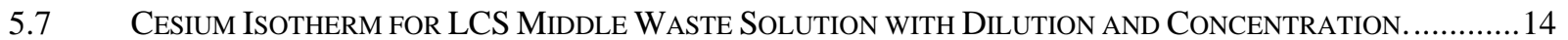

6.0 ORNL SINGLE BATCH CONTACT EXPERIMENTS ........................................................................17

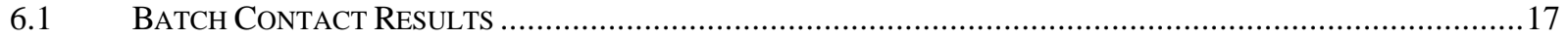

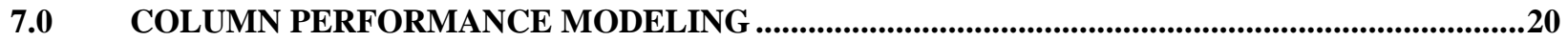

8.0 CESIUM COLUMN INVENTORY ANALYSIS FOR IE-910 AND IE-911...................................29

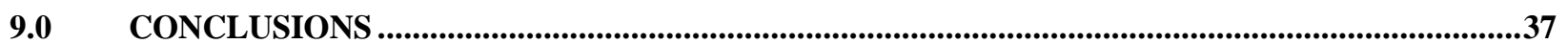

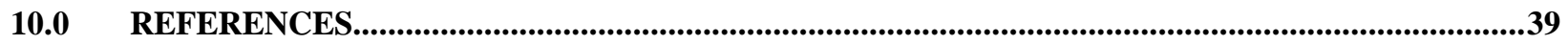




\section{LIST OF TABLES}

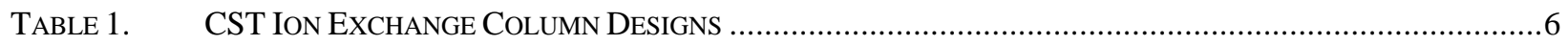

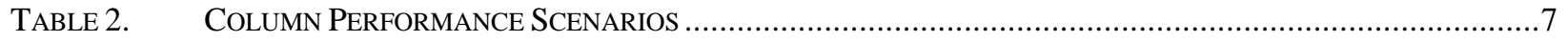

TABlE $3 . \quad$ COMPOSITION OF NOMINAL LOW CURIE SALT SOLUTIONS........................................................

Table 4. LCS Middle Composition with Variation in Cesium, Potassium and Hydroxide

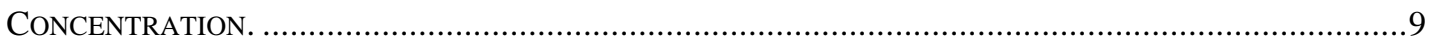

TABLE 5. LCS MidDLE COMPOSITION WITH DILUTION AND CONCENTRATION .................................................

TABle 6. VOLUME OF WASTE PROCESSED FOR VARIOUS TANK FEED SOLUTIONS AT A CESIUM BREAKTHROUGH OF

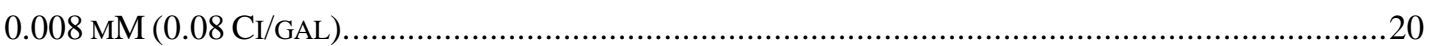

TABLE 7. AVERAGE CS-137 LOAdING For VARIOUS TANK FEEd SOLUTIONS. .................................................29 


\section{LIST OF FIGURES}

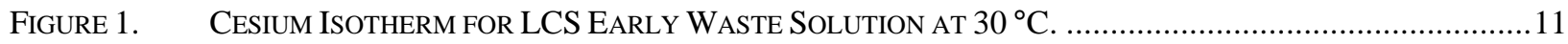

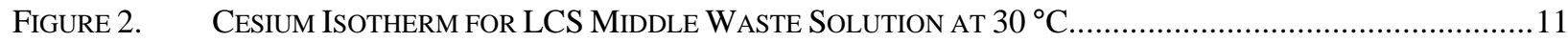

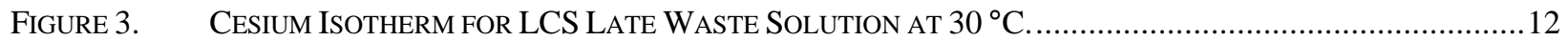

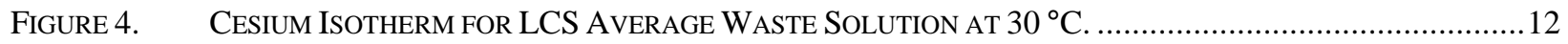

Figure 5. CESIUM ISOTHERM FOR RECENT TANK 41H DiSSOLVED SALT SOLUTION AT $30^{\circ} \mathrm{C} \ldots \ldots \ldots \ldots \ldots \ldots \ldots \ldots . . . . . . . . . . .13$

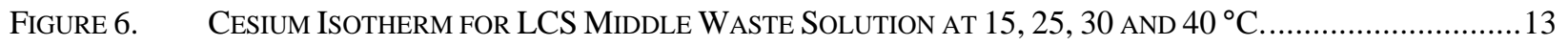

Figure 7. CESIUM ISOTHERM FOR LCS MidDLE WASTE SOLUTION WITH VARIATION IN POTASSIUM

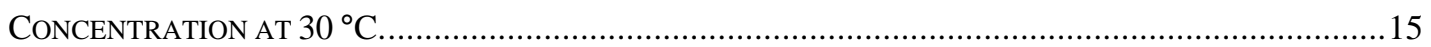

FIGURE 8. CESIUM ISOTHERM FOR LCS MidDLE SALT SOLUTION WITH VARIATION IN HYDROXIDE

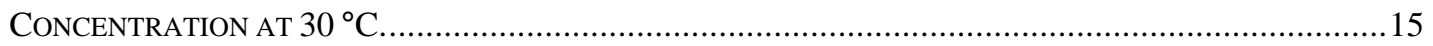

Figure 9. CESIUM ISOTHERM FOR LCS MidDle SALt SOLUTION With DILUTION To $\left[\mathrm{NA}^{+}\right]=6 \mathrm{M}$ AND

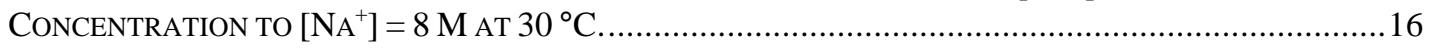

FIGURE 10. COMPARISON OF ORNL SINGLE BATCH CONTACT EXPERIMENT TO ZAM ISOTHERM FOR LCS EARLY

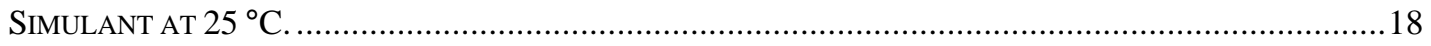

Figure 11. COMPARISON OF ORNL Single BATCH CONTACT EXPERIMENT TO ZAM ISOTHERM FOR LCS MidDLE

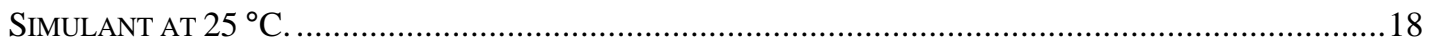

FIGURE 12. COMPARISON OF ORNL SINGLE BATCH CONTACT EXPERIMENT TO ZAM ISOTHERM FOR LCS LATE

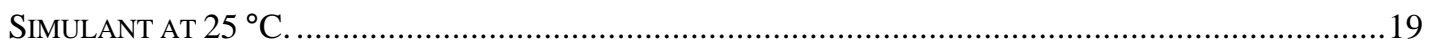

FIGURE 13. COMPARISON OF ORNL SINGLE BATCH CONTACT EXPERIMENT TO ZAM ISOTHERM FOR LCS AVERAGE

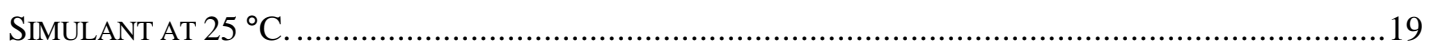

Figure 14. Cesium Breakthrough Curves for lCS Early, Middle, Late and Average Salt Solutions at

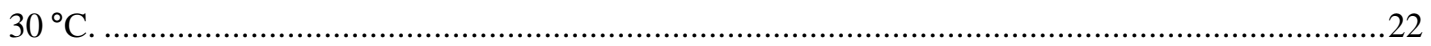

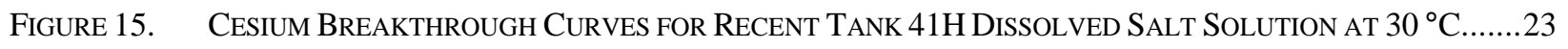

Figure 16. Cesium Breakthrough Curves for LCS Middle SAlt Solution Flowing at 8, 20 25, 30 and 40

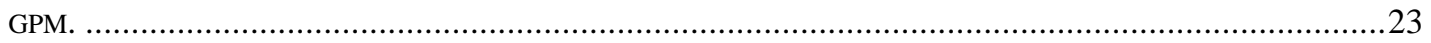

Figure 17. Cesium BreakThrough CURVES For LCS MiddLe SAlt Solution AT 15, 30 AND $40{ }^{\circ} \mathrm{C} \ldots \ldots \ldots \ldots \ldots . . .24$

Figure 18. Cesium BreakThrough CuRves For LCS Middle Waste Solution with Cesium

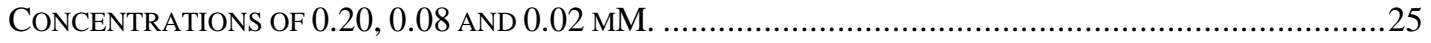

Figure 19. Cesium Breakthrough CuRVES FOR LCS Middle Waste SOlution With Potassium

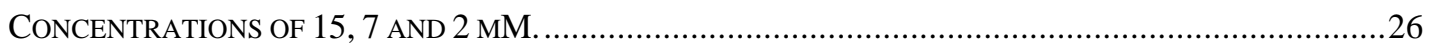

Figure 20. Cesium Breakthrough CuRves for LCS Middle SAlt Solution with Hydroxide

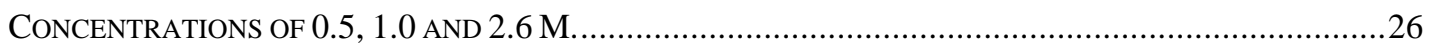

Figure 21. Cesium Breakthrough CURVES FOR LCS Middle WASTE SOlution With Dilution to A Sodium

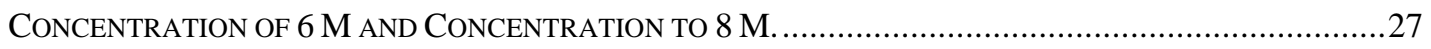

Figure 22. Cesium Breakthrough CuRves for LCS Middle SAlt Solution with Three Different IX

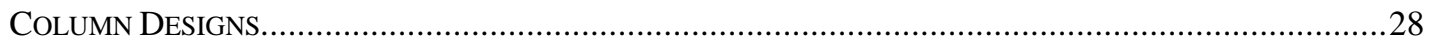

Figure 23. CST AXIAl Cs-137 LoAding Profile for LCS EARLy Waste Solution at a Bucket Average

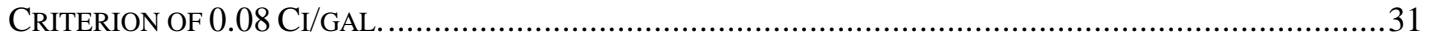

Figure 24. CST AXIAl Cs-137 LOAding Profile For LCS Middle WaSte Solution AT A BucKet Average

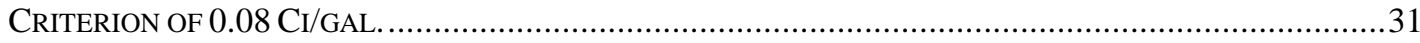

Figure 25. CST AXial Cs-137 LoAding Profile for LCS Late Waste Solution at a Bucket AVerage

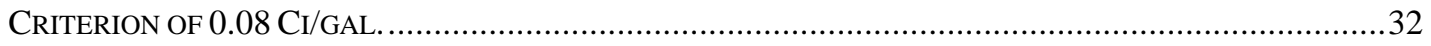

Figure 26. CST AXial Cs-137 LoAding Profile for LCS AVERAge Waste Solution at a Bucket Average

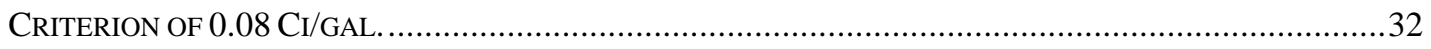

Figure 27. CST AXIAl Cs-137 LoAding Profile for ReCENT TANK 41H Dissolved Salt Solution AT a

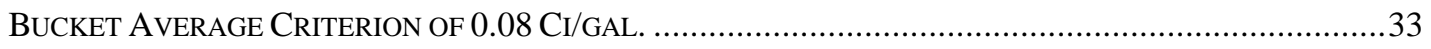

Figure 28. CST AXial Cs-137 LoAding Profile for LCS Middle Waste Solution Flowing AT 8, 20, 25, 30

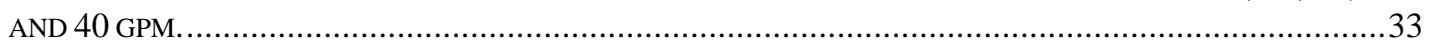

Figure 29. CST AXIAL Cs-137 LoAding Profile For LCS Middle Waste Solution AT 15, 30 AND $40{ }^{\circ} \mathrm{C} . . . . .34$

Figure 30. CST AXial Cs-137 LoAding Profile For LCS Middle Waste SOlution AT Cesium CONCENTRATIONS OF $0.20,0.08$ AND $0.02 \mathrm{MM}$. . .34 
Figure 31. CST Axial Cs-137 LoAding Profile for LCS Middle Waste Solution at Potassium

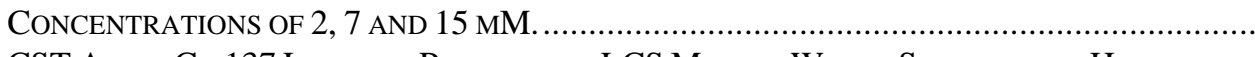

Figure 32. CST AXIAL Cs-137 LoAding Profile FOR LCS Middle WASTE SOlution AT Hydroxide

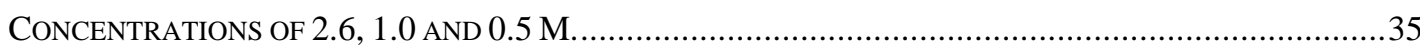

Figure 33. CST AXIAL Cs-137 LoAding Profile FOR LCS MidDLE WASTE SOLUTION AT Sodium CONCENTRATIONS OF 6, 7 AND $8 \mathrm{M}$ (DilUTION AND CONCENTRATION). ...........................................

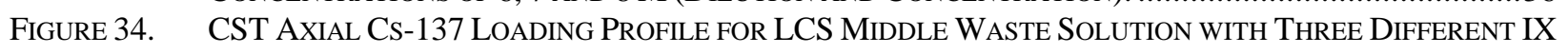

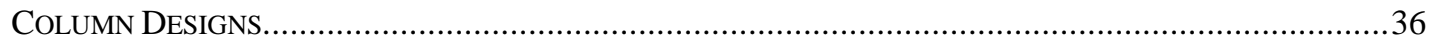




\subsection{Executive Summary}

Savannah River Technology Center (SRTC) researchers modeled ion exchange removal of cesium from dissolved salt waste solutions. The results assist in evaluating proposed configurations for an ion exchange process to remove residual cesium from low curie waste streams. A process for polishing (i.e., removing small amounts) of cesium may prove useful should supernate draining fail to meet the Low Curie Salt (LCS) target limit of $0.1 \mathrm{Ci}$ of Cs-137 per gallon of salt solution. Researchers investigated the performance of UOP IONSIV ${ }^{\circledR}$ IE-911 Crystalline Silicotitanate (CST) sorbent using the equilibrium Zheng, Anthony, and Miller (ZAM) isotherm model and the dynamic VERSE-LC column transport model (Whitley et al., 1998). Cesium loading isotherms and column breakthrough curves for Low Curie dissolved salt solutions were computed to provide performance predictions for various column designs. Performance calculations generated the following results and conclusions.

- Performance modeling supported the design effort that culminated in the selection of a 432gal column, 28 inches diameter and 15 feet long.

A 432-gal column balances concerns about column heating and the operating cycle (i.e., the time between column change outs). The column packing must be changed after 2 to 17 days of operation at $25 \mathrm{gpm}$.

- The ion exchange column will process a variety of waste compositions.

Four waste compositions reflecting potential variation in dissolved salt cake wastes and Tank $41 \mathrm{H}$ were examined.

Modeling results indicate that a 432-gallon column can process between 76,000 and 591,000 gallons of waste at an instantaneous cesium breakthrough of $0.08 \mathrm{Ci} / \mathrm{gal}$.

Modeling results indicate that a 432-gallon column can process between 127,000 and 905,000 gallons of waste at a bucket average cesium breakthrough of $0.08 \mathrm{Ci} / \mathrm{gal}$.

Cs-137 loadings on the 432 gallon CST columns range between 34 and $627 \mathrm{Ci} / \mathrm{L}$.

- Modeling quantified the impacts of variations in concentrations of important waste components.

Increasing the initial cesium or sodium concentration reduces the volume that can be processed.

Variation of potassium concentration over the range expected in the LCS feeds has a minimal impact on the volume of waste processed.

Increasing the concentration of hydroxide improves the volume of waste that can be processed per column loading. 
Small Column Ion Exchange Analysis for Removal of Cesium from SRS

- Modeling showed the effects of changes in several processing parameters allowing for selection of optimal process conditions.

Lowering the flow rate, temperature, or required decontamination factor increases the amount of waste that a column can process. 


\subsection{Introduction and Background}

The Closure Business Unit (CBU) of the Westinghouse Savannah River Company (WSRC) proposes to send low curie salt waste directly to the Saltstone facility (in support of lifecycle cost reduction to salt waste processing). Progress toward this goal began in 2002 with supernate removal from Tank 41H. Supernate draining removes soluble cesium from the tank, leaving behind a low activity salt cake. Dissolution of the low activity salt cake yields a dissolved salt solution containing a low concentration of cesium. In the CBU proposal, low curie salt solution goes directly to Tank $50 \mathrm{H}$ and then to the Saltstone facility for incorporation into grout and on site burial. If strontium and actinide concentrations exceed Saltstone waste acceptance criteria, then the salt solution goes to the Actinide Removal Process (ARP) before transfer to Saltstone.

If any of the low curie salt solution fails to meet the target Cs-137 concentration $(\bullet 0.1 \mathrm{Ci} / \mathrm{gal})$, then a polishing operation to remove small amounts of cesium could avoid returning of the solution to waste storage. Potential cesium polishing methods include batch or column processes using an appropriate sorbent. The leading sorbent candidate is Crystalline Silicotitanate (CST), either in the powder form (UOP IONSIV ${ }^{\circledR}$ IE-910) or in the granular, engineered form (UOP IONSIV $^{\circledR}$ IE-911). Researchers at Texas A\&M University and Sandia National Laboratory discovered the sorbent, and UOP, LLC personnel developed the binder technology for producing a granular form suitable for ion exchange column processing.

This report provides calculations of expected performance of IONSIV ${ }^{\circledR}$ IE-910 and IE-911 with low curie dissolved salt solutions in single-batch and column processes. The DOE Office of Accelerated Cleanup funded this work through an Oak Ridge National Laboratory proposal titled "Small Column Ion Exchange System Utilizing Crystalline Silicotitanate for Cesium Removal from Low Curie Salt Waste".

\section{$2.1 \quad$ Objectives}

- Provide information for determining the column change-out frequency and Cs-137 loading levels expected from a small column IX process for Low Curie Salt (LCS) waste. How often must the column packing be changed? What is the cesium loading on the loaded CST column?

- Show that the process can handle a range of wastes. There are four proposed waste compositions: LCS Early, LCS Middle, LCS Late and LCS Average (Walker, 2003). Early, Middle and Late refers to the point-in-time of processing the waste stream from the LCS tanks. The "Average" represents a composite average of all LCS tank compositions. In addition, a recent Tank $41 \mathrm{H}$ dissolved salt solution composition is also considered (Martino, 2003). At what point (i.e., increasing DF requirement) does the process become unattractive or unworkable?

- Determine the effects of the following on the change-out frequency and loading: 
1. Flow rate: Determine the impact of variations in flow rate from 8 to $40 \mathrm{gpm}$. The reference flow rate is $30 \mathrm{gpm}$.

2. Temperature: Determine the impact of variations in temperature from 15 to $40{ }^{\circ} \mathrm{C}$. The reference temperature is $30^{\circ} \mathrm{C}$.

3. Competitor ion variability: Determine the impact on cesium breakthrough and loading performance due to variability in initial feed cesium, sodium, potassium and hydroxide concentrations from nominal conditions.

4. Column size: Determine the impact of column size (diameter and length) on column performance. The reference column design has an effective diameter of 26.6 inches and a column length of 15 feet.

All modeling objectives were met and results are presented within this report.

\subsection{Description of Modeling Codes}

The Zheng, Anthony, and Miller (1996) (algorithm referred to as ZAM) solid-liquid equilibrium model for powder CST (IE-910) was used to generate cesium isotherm points for each LCS waste composition and a recent Tank $41 \mathrm{H}$ dissolved salt solution at a given temperature. The configuration controlled Version 4 of ZAM was used to compute fourteen solid-equilibrium points along the cesium loading curve for each waste composition. Each cesium loading curve (cesium CST solid loading versus final aqueous cesium concentration) was fitted to a 2-parameter single-component Fruendlich/Langmuir hybrid isotherm (Whitley, 1998). This algebraic form of the isotherm was chosen to be used by VERSE-LC to perform the cesium column breakthrough

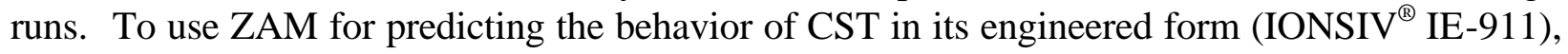
a correction factor accounting for the inert binding material is included (the total cesium capacity of IE-910 is reduced by a dilution factor).

The OLI Systems, Inc. StreamAnalyzer Version 1.2 (Build 1.2.0.24) was used to compute tank waste solution liquid densities and viscosities. The liquid densities are required by ZAM to convert input solution molarity to molality. The liquid viscosity is used to correct the infinity dilute free stream binary diffusion coefficients based on the Stokes-Einstein equation.

The VERSE-LC v7.80 ion exchange model was used to calculate cesium breakthrough and loading curves for IONSIV ${ }^{\circledR}$ IE-911 columns with LCS waste and a recent Tank $41 \mathrm{H}$ dissolved salt solution. VERSE-LC is a one dimensional transport model that includes solid-liquid equilibrium, axial dispersion, film mass transfer, and pore diffusion.

\subsection{Modeling Assumptions}

In order to model the column performance using CST, several modeling assumptions were made. The key modeling assumptions chosen are: 
- Steady-state Darcy flow in a saturated isothermal porous media (plug flow). The operating range of proposed superficial liquid velocities is within the Blake-Kozenzy portion of the Ergun equation and indicates that laminar (or Darcian) flow through the packed column is an acceptable assumption for the correlations employed.

- Uniform and constant intrinsic permeability throughout the resin bed.

- Bed porosity is set to current best estimate value of 0.50 , where the column is assumed to be uniformly packed (Hamm et al., 2002).

- The methodology for computation of free stream (Brownian) and pore diffusion coefficients of cesium in electrolytic solutions is conservative.

- A dilution factor for IONSIV ${ }^{\circledast}$ IE-911 of $68 \%$ of its original IE-910 powder value is used. (Hamm et al., 2002). The recent ORNL CST batch contact tests (Taylor et al., 2003) with IONSIV $^{\circledR}$ IE-911 suggests no dilution factor is required. The customer (D. D. Walker) made the decision to use the conservative dilution factor for the analysis.

\subsection{Data Needs}

To perform the small column ion exchange analyses, the following input data needs were required:

- Column dimensions (i.e. OD/ID, length, internal structures) of the proposed ion exchange column designs.

- Nominal salt solution volumetric liquid flow rate and temperature.

- Nominal compositions of the LCS Early, Middle, Late, and Average salt solutions. The nominal composition of the recent Tank $41 \mathrm{H}$ dissolved salt solution.

- Matrix of off-nominal salt solution composition, liquid flow rate and liquid temperature for sensitivity studies.

- Salt solution liquid density and viscosity as a function of temperature.

- Fruendlich/Langmuir hybrid cesium isotherm parameters.

- Cesium breakthrough criterion (i.e. bucket average or instantaneous exit value). 


\subsection{LCS Column Designs and Performance Scenarios}

\subsection{Column Designs}

Five different CST ion exchange column designs were considered in this study. The initial column design was a 551 gal column with a 30 inch diameter, 15 feet long and operating at a feed rate of $30 \mathrm{gpm}$ (Design 1). Heat transfer analysis of this column during the loss of normal flow revealed inadequate cooling of the CST resin by radial thermal conduction to the outer wall of the column. To mitigate this problem, a second design (Design 2) was considered with a reduction in diameter to 26 inch, thus reducing the radial conduction path and CST inventory to 414 gal. Design 2 was reanalyzed and failed to provide sufficient cooling of the CST by passive means. Therefore, a third design (Design 3) was introduced with forced convection cooling down the center of the column using a 6 inch OD cooling pipe. The outer diameter of the column was increased to 28 inches with a 5/16 inch wall thickness to provide a CST sorbent inventory of 432 gal. Design 3 is designated the nominal column design in this study. Two other off-nominal column designs were considered. Design 4 is a 296 gal column with a 22 inch diameter, 15 feet long and no forced convection cooling. Design 5 is the nominal column design where the length of the column has been reduced to 10 feet. Table 1 is a summary of the column designs considered in this report. The designator (equiv) for column designs 3 and 5 refers to the equivalent cylindrical column design without any inner cooling pipe (an equivalent column id is computed to provide the same sorbent volume as the design with the inner cooling pipe).

Table 1. CST Ion Exchange Column Designs

\begin{tabular}{|c|c|c|c|c|c|c|c|}
\hline $\begin{array}{l}\text { Column } \\
\text { Design }\end{array}$ & $\begin{array}{c}\text { Column } \\
\text { Length } \\
\text { (ft) }\end{array}$ & $\begin{array}{l}\text { OD } \\
\text { (in) }\end{array}$ & $\begin{array}{l}\text { Outer Core } \\
\text { Wall } \\
\text { (in) }\end{array}$ & $\begin{array}{l}\text { ID } \\
\text { (in) }\end{array}$ & $\begin{array}{c}\text { Inner Core } \\
\text { OD } \\
\text { (in) }\end{array}$ & $\begin{array}{c}\text { Column } \\
\text { L/D }\end{array}$ & $\begin{array}{c}\text { Column } \\
\text { Volume } \\
\text { (gal/L) }\end{array}$ \\
\hline 1 & 15.0 & 30.000 & 0 & 30.000 & 0 & 6.0 & $551 / 2086$ \\
\hline 2 & 15.0 & 26.000 & 0 & 26.000 & 0 & 6.9 & $414 / 1567$ \\
\hline 3 & 15.0 & 28.000 & 0.3125 & 27.375 & 6.625 & & $432 / 1635$ \\
\hline 3 (equiv) & 15.0 & 26.561 & 0 & 26.561 & 0 & 6.8 & $432 / 1635$ \\
\hline 4 & 15.0 & 22.000 & 0 & 22.000 & 0 & 8.2 & $296 / 1120$ \\
\hline 5 & 10.0 & 28.000 & 0.3125 & 27.375 & 6.625 & & $288 / 1090$ \\
\hline 5 (equiv) & 10.0 & 26.561 & 0 & 26.561 & 0 & 4.5 & $288 / 1090$ \\
\hline
\end{tabular}

\subsection{Column Performance Scenarios}

Twenty-one column performance scenarios were considered in this study. The majority of the scenarios (17 of 21) are with the LCS Middle waste composition. The LCS Middle waste composition yields the earliest cesium breakthrough of the LCS waste compositions. Table 2 
WESTINGHOUSE SAVANNAH RIVER COMPANY

Small Column Ion Exchange Analysis for Removal of Cesium from SRS Low Curie Salt Solution Using Crystalline Silicotitanate (CST) Resin
Report: WSRC-TR-2003-00430

Revision (Date): $\quad 0(12 / 03)$

Page:

provides a list of the column performance scenarios considered in this report (i.e., the most adverse isotherm).

Table 2. Column Performance Scenarios

\begin{tabular}{|c|c|c|c|c|c|}
\hline $\begin{array}{c}\text { Scenario } \\
\text { No. }\end{array}$ & $\begin{array}{l}\text { Column } \\
\text { Design }\end{array}$ & $\begin{array}{l}\text { Tank } \\
\text { Feed }\end{array}$ & $\begin{array}{c}\text { Composition } \\
\text { Variability }\end{array}$ & $\begin{array}{c}\text { Feed } \\
\text { Flow (gpm) }\end{array}$ & $\begin{array}{c}\text { Feed } \\
\text { Temp (C) }\end{array}$ \\
\hline 1 & 3 & LCS Early & Nominal & 25 & 30 \\
\hline 2 & 3 & LCS Middle & Nominal & 25 & 30 \\
\hline 3 & 3 & LCS Late & Nominal & 25 & 30 \\
\hline 4 & 3 & LCS Average & Nominal & 25 & 30 \\
\hline 5 & 3 & Tank $41 \mathrm{H}$ & Nominal & 25 & 30 \\
\hline 6 & 3 & LCS Middle & Nominal & 8 & 30 \\
\hline 7 & 3 & LCS Middle & Nominal & 20 & 30 \\
\hline 8 & 3 & LCS Middle & Nominal & 30 & 30 \\
\hline 9 & 3 & LCS Middle & Nominal & 40 & 30 \\
\hline 10 & 3 & LCS Middle & Nominal & 25 & 15 \\
\hline 11 & 3 & LCS Middle & Nominal & 25 & 40 \\
\hline 12 & 3 & LCS Middle & Low $\mathrm{Cs}^{+}$ & 25 & 30 \\
\hline 13 & 3 & LCS Middle & $\mathrm{High} \mathrm{Cs}^{+}$ & 25 & 30 \\
\hline 14 & 3 & LCS Middle & Low $\mathrm{K}^{+}$ & 25 & 30 \\
\hline 15 & 3 & LCS Middle & $\operatorname{High~K}^{+}$ & 25 & 30 \\
\hline 16 & 3 & LCS Middle & Low $\mathrm{OH}^{-}$ & 25 & 30 \\
\hline 17 & 3 & LCS Middle & High $\mathrm{OH}^{-}$ & 25 & 30 \\
\hline 18 & 3 & LCS Middle & Diluted & 25 & 30 \\
\hline 19 & 3 & LCS Middle & Concentrated & 25 & 30 \\
\hline 20 & 4 & LCS Middle & Nominal & 25 & 30 \\
\hline 21 & 5 & LCS Middle & Nominal & 25 & 30 \\
\hline
\end{tabular}




\subsection{Waste Compositions}

Table 3 lists four nominal Low Curie Salt waste compositions examined in this work (Walker, 2003). The compositions are charge-balanced and only account for species adequately addressed by ZAM. In addition, a recent Tank $41 \mathrm{H}$ dissolved salt solution is considered in this study (Martino et al., 2003). LCS Early, Middle and Late refer to the point-in-time of processing the waste stream from the LCS tanks (i.e., early versus late tank retrieval). The "Average" represents a composite average of all LCS tank compositions. Sections 4.1 and 4.2 show the LCS Middle waste composition where key ion exchange competitors have been perturbed about their nominal values. We have omitted minor components and calculated total cesium concentrations from the Cs-137 activity using the specific activity of Cs-137 ,87 Ci/g (ORNL, 1995), and assuming Cs137 comprises 22 mole \% of the total cesium (Dimenna et al., 2001).

Table 3. Composition of Nominal Low Curie Salt Solutions.

\begin{tabular}{|c|c|c|c|c|c|c|}
\hline $\begin{array}{c}\text { Ion } \\
\text { Category }\end{array}$ & Species & $\begin{array}{l}\text { LCS Early } \\
\text { Nominal } \\
\text { (M) }\end{array}$ & $\begin{array}{c}\text { LCS Middle } \\
\text { Nominal } \\
\text { (M) }\end{array}$ & $\begin{array}{c}\text { LCS Late } \\
\text { Nominal } \\
\text { (M) }\end{array}$ & $\begin{array}{c}\text { LCS Average } \\
\text { Nominal } \\
\text { (M) }\end{array}$ & $\begin{array}{c}\text { Tank 41H } \\
\text { Nominal } \\
\text { (M) }\end{array}$ \\
\hline \multirow[t]{4}{*}{ Cations ${ }^{*}$} & $\mathrm{Na}^{+}$ & 7.0000 & 7.0000 & 4.2000 & 6.0000 & 7.9001 \\
\hline & Total $\mathrm{Cs}^{+}$ & $8.0000 \mathrm{E}-05$ & $8.0000 \mathrm{E}-05$ & $8.0000 \mathrm{E}-05$ & $2.0000 \mathrm{E}-05$ & $3.8000 \mathrm{E}-05$ \\
\hline & $\begin{array}{c}\text { Cs-137 } \\
\text { (Ci/gal) }\end{array}$ & 0.08 & 0.08 & 0.08 & 0.02 & 0.038 \\
\hline & $\mathbf{K}^{+}$ & 0.0070 & 0.0070 & 0.0042 & 0.0060 & 0.0079 \\
\hline \multirow[t]{9}{*}{ Anions } & $\mathrm{OH}^{\bullet}$ (free) & 1.9000 & 1.0000 & 0.3000 & 1.6600 & 0.8500 \\
\hline & $\mathrm{NO}_{3}{ }^{\circ}$ & 2.6000 & 4.0000 & 0.5000 & 2.3000 & 4.9010 \\
\hline & $\mathrm{NO}_{2}{ }^{\circ}$ & 0.9000 & 0.1000 & 0.0200 & 0.7100 & 0.2400 \\
\hline & $\mathrm{Al}(\mathrm{OH})_{4}{ }^{\bullet}$ & 1.2000 & 0.4000 & 0.0010 & 0.3700 & 0.4500 \\
\hline & $\mathrm{CO}_{3}{ }^{2 \cdot}$ & 0.1300 & 0.4500 & 1.2000 & 0.1200 & 0.4500 \\
\hline & $\mathrm{SO}_{4}{ }^{2 \cdot}$ & 0.0500 & 0.2970 & 0.4880 & 0.1620 & 0.2300 \\
\hline & $\mathrm{PO}_{4}{ }^{3 \cdot}$ & 0.0070 & 0.0020 & 0.0010 & 0.1320 & 0.0350 \\
\hline & $\mathrm{Cl}^{\circ}$ & 0.01908 & 0.00008 & 0.0008 & 0.00002 & 0.001038 \\
\hline & $\mathbf{F}^{\cdot}$ & 0.0070 & 0.0070 & 0.0042 & 0.0060 & 0.0010 \\
\hline
\end{tabular}

\subsection{LCS Middle Composition (Cesium, Potassium and Hydroxide Concentration Variation)}

Table 4 lists the LCS Middle composition where the cesium, potassium and hydroxide concentrations have been varied about their nominal values per guidance by the customer. 
WESTINGHOUSE SAVANNAH RIVER COMPANY

Small Column Ion Exchange Analysis for Removal of Cesium from SRS Low Curie Salt Solution Using Crystalline Silicotitanate (CST) Resin
Report:

WSRC-TR-2003-00430

Revision (Date):

$0(12 / 03)$

Page: 9 of 39

Table 4. LCS Middle Composition with Variation in Cesium, Potassium and Hydroxide Concentration.

\begin{tabular}{|c|c|c|c|}
\hline \multirow{2}{*}{ Varied Species } & \multicolumn{3}{|c|}{ Concentrations (M) } \\
\cline { 2 - 4 } & Low & Nominal & High \\
\hline \hline Total Cs & $2.0000 \mathrm{E}-05$ & $8.0000 \mathrm{E}-05$ & $2.0000 \mathrm{E}-04$ \\
\hline $\mathbf{K}^{+}$ & 0.0020 & 0.0070 & 0.0150 \\
\hline $\mathbf{O H}^{+}$(free) & 0.5000 & 1.0000 & 2.6000 \\
\hline
\end{tabular}

\subsection{LCS Middle Composition (Dilution and Concentration)}

Table 5 lists the LCS Middle Composition where the solution has been diluted to a target sodium concentration of $6 \mathrm{M}$ and concentrated to $8 \mathrm{M}$ per guidance by the customer.

Table 5. LCS Middle Composition with Dilution and Concentration

\begin{tabular}{|c|c|c|c|c|}
\hline $\begin{array}{c}\text { Ion } \\
\text { Category }\end{array}$ & Species & $\begin{array}{c}\text { LCS Middle } \\
\text { Diluted } \\
\text { (M) }\end{array}$ & $\begin{array}{c}\text { LCS Middle } \\
\text { Nominal } \\
\text { (M) }\end{array}$ & $\begin{array}{c}\text { LCS Middle } \\
\text { Concentrated } \\
\text { (M) }\end{array}$ \\
\hline \multirow[t]{4}{*}{ Cations* } & $\mathrm{Na}^{+}$ & 6.0000 & 7.0000 & 8.0000 \\
\hline & Total $\mathrm{Cs}^{+}$ & $6.8571 \mathrm{E}-05$ & $8.0000 \mathrm{E}-05$ & $9.1429 \mathrm{E}-05$ \\
\hline & Cs-137 (Ci/gal) & 0.07 & 0.08 & 0.09 \\
\hline & $\mathbf{K}^{+}$ & 0.0060 & 0.0070 & 0.0080 \\
\hline \multirow[t]{9}{*}{ Anions } & $\mathrm{OH}^{\bullet}$ (free) & 0.8571 & 1.0000 & 1.1429 \\
\hline & $\mathrm{NO}_{3}{ }^{\circ}$ & 3.4286 & 4.0000 & 4.5714 \\
\hline & $\mathrm{NO}_{2}{ }^{\circ}$ & 0.0857 & 0.1000 & 0.1143 \\
\hline & $\mathrm{Al}(\mathrm{OH})_{4}{ }^{\circ}$ & 0.3429 & 0.4000 & 0.4571 \\
\hline & $\mathrm{CO}_{3}{ }^{2 \cdot}$ & 0.3857 & 0.4500 & 0.5143 \\
\hline & $\mathrm{SO}_{4}{ }^{2 \cdot}$ & 0.2546 & 0.2970 & 0.3394 \\
\hline & $\mathrm{PO}_{4}{ }^{3 \bullet}$ & 0.0017 & 0.0020 & 0.0023 \\
\hline & $\mathrm{Cl}^{\circ}$ & 0.00007 & 0.00008 & 0.00009 \\
\hline & $\mathbf{F}^{\cdot}$ & 0.0060 & 0.0070 & 0.0080 \\
\hline
\end{tabular}




\subsection{ZAM Isotherms}

A three step process generated the cesium sorption data in a form suitable for column modeling. First, the ZAM model is used to calculate equilibrium data for cesium sorbed on IONSIV ${ }^{\circledR}$ IE-910 for each of the specific waste compositions listed in Section 4. Second, the IONSIV ${ }^{\circledR}$ IE-910 data was fitted to an algebraic equation for each case study. Third, a dilution factor applied to the IONSIV $^{\circledR}$ IE-910 equation provided an equation for estimating IONSIV $^{\circledR}$ IE-911 performance. Column modeling with the VERSE-LC code used the IONSIV ${ }^{\circledR}$ IE-911 isotherms.

\subsection{Cesium Loading Curves}

Cesium loading curves were generated for IONSIV ${ }^{\circledR}$ IE-910 and IE-911. The ZAM model calculated the loading data for IE-910 using the solution compositions given in Section 4. Figures were generated showing the ZAM data and algebraic fit of the data. These include the isotherm fitted to the ZAM data (IE-910) and an isotherm for IE-911. The IE-911 isotherm includes a dilution factor. The $68 \%$ dilution factor applied to the ZAM results represents a $32 \%$ lower capacity of IE-911 compared to ZAM predictions. Conflicting data exists concerning the magnitude of this dilution factor. The present calculations conservatively include this factor. If the dilution factor equals unity (as suggested by some results with actual waste), then column performance (volume of waste processed per unit volume of sorbent) will exceed the predictions provided within this report

\subsection{Cesium Isotherm for LCS Waste Solutions.}

Figures 1 through 4 represent the cesium isotherm for the LCS Early, Middle, Late and Average waste solutions, respectively. The nominal cesium feed concentration of $0.08 \mathrm{mM}$ is also plotted along with the isotherms in each figure. The LCS Middle waste solution (Figure 2) provides the lowest cesium loading for a given equilibrium cesium concentration (i.e., a bounding isotherm). Therefore the LCS Middle waste solution will be the nominal isotherm used when assessing the impact of liquid flowrate, temperature, composition variability and column geometry changes on cesium breakthrough performance.

\subsection{Cesium Isotherm for recent Tank 41H Dissolved Salt Solution.}

Figure 5 shows the cesium isotherm for a recent Tank $41 \mathrm{H}$ dissolved salt solution. The nominal cesium feed concentration of $0.038 \mathrm{mM}$ is also plotted along with the isotherm in the figure. The cesium isotherm yields lower cesium loadings than the LCS Middle waste solution isotherm because of lower hydroxide, higher sodium, and higher potassium concentrations, respectively.

\subsection{Cesium Isotherm for LCS Middle Waste Solution at Various Temperatures.}

Figure 6 shows the cesium isotherm for LCS Middle waste solution at 15, 25, 30 and $40{ }^{\circ} \mathrm{C}$. The expected nominal operating liquid temperature is $30^{\circ} \mathrm{C}$. The cesium loading monotonically 


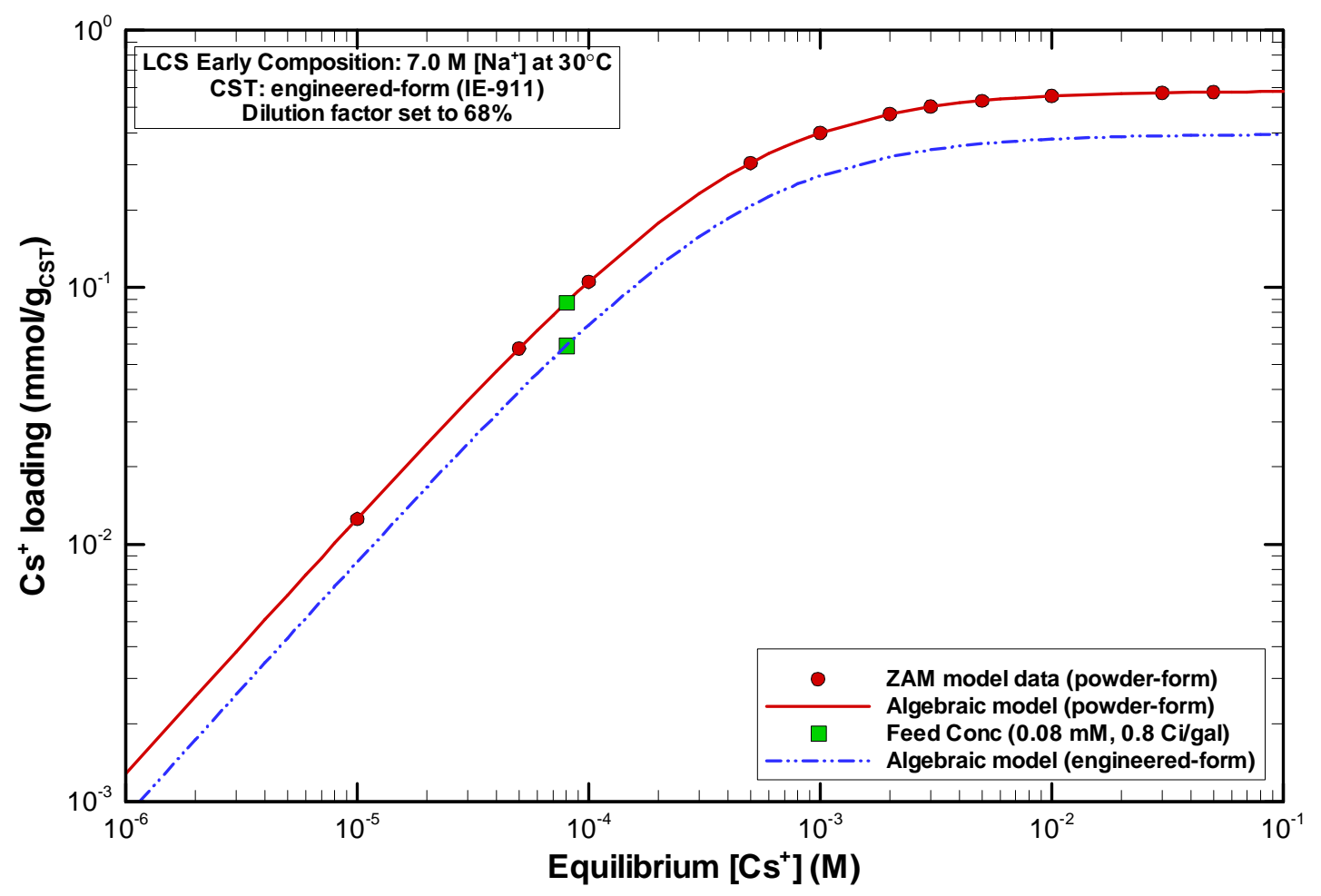

Figure 1. Cesium Isotherm for LCS Early Waste Solution at $30^{\circ} \mathrm{C}$.

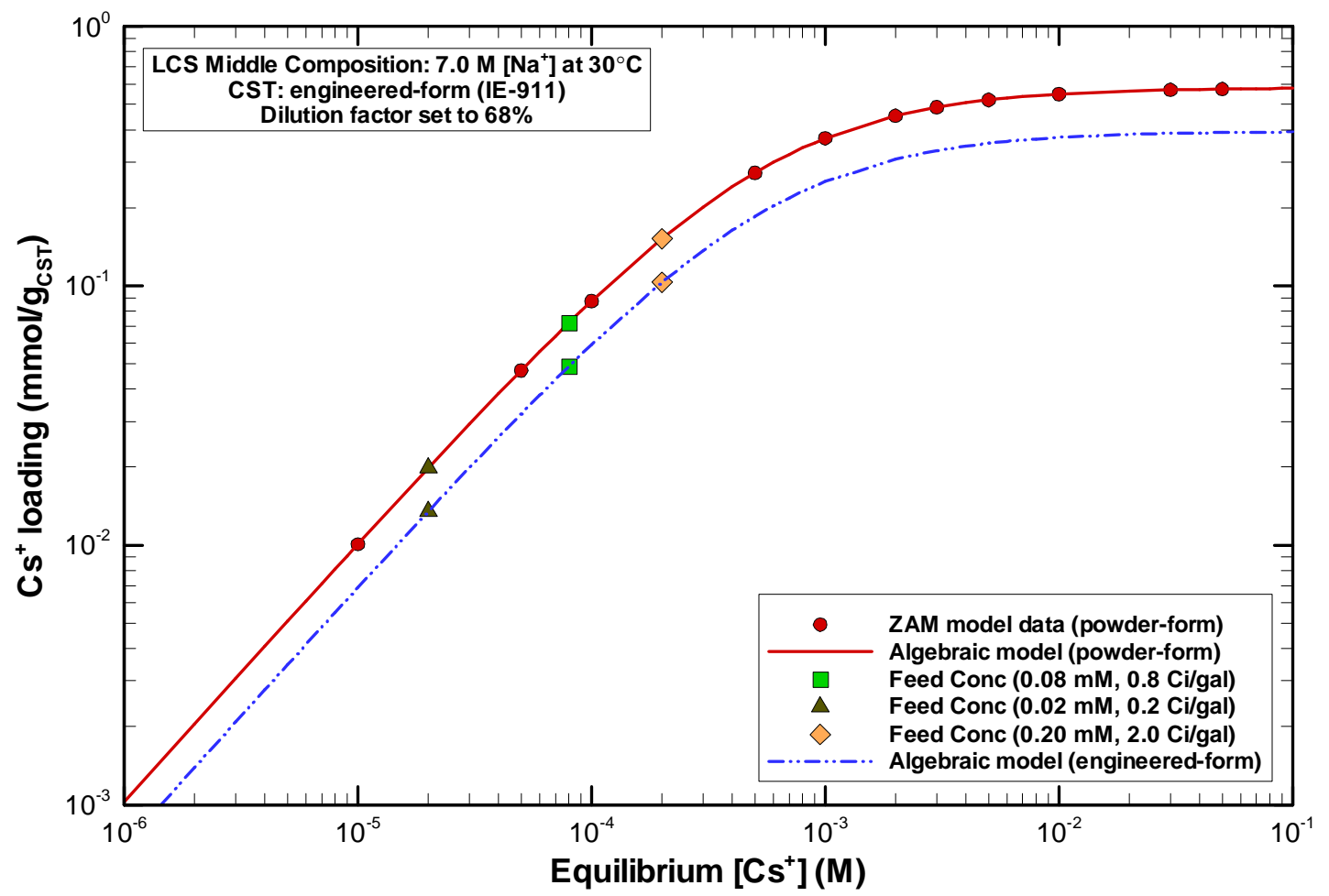

Figure 2. Cesium Isotherm for LCS Middle Waste Solution at $30{ }^{\circ} \mathrm{C}$. 


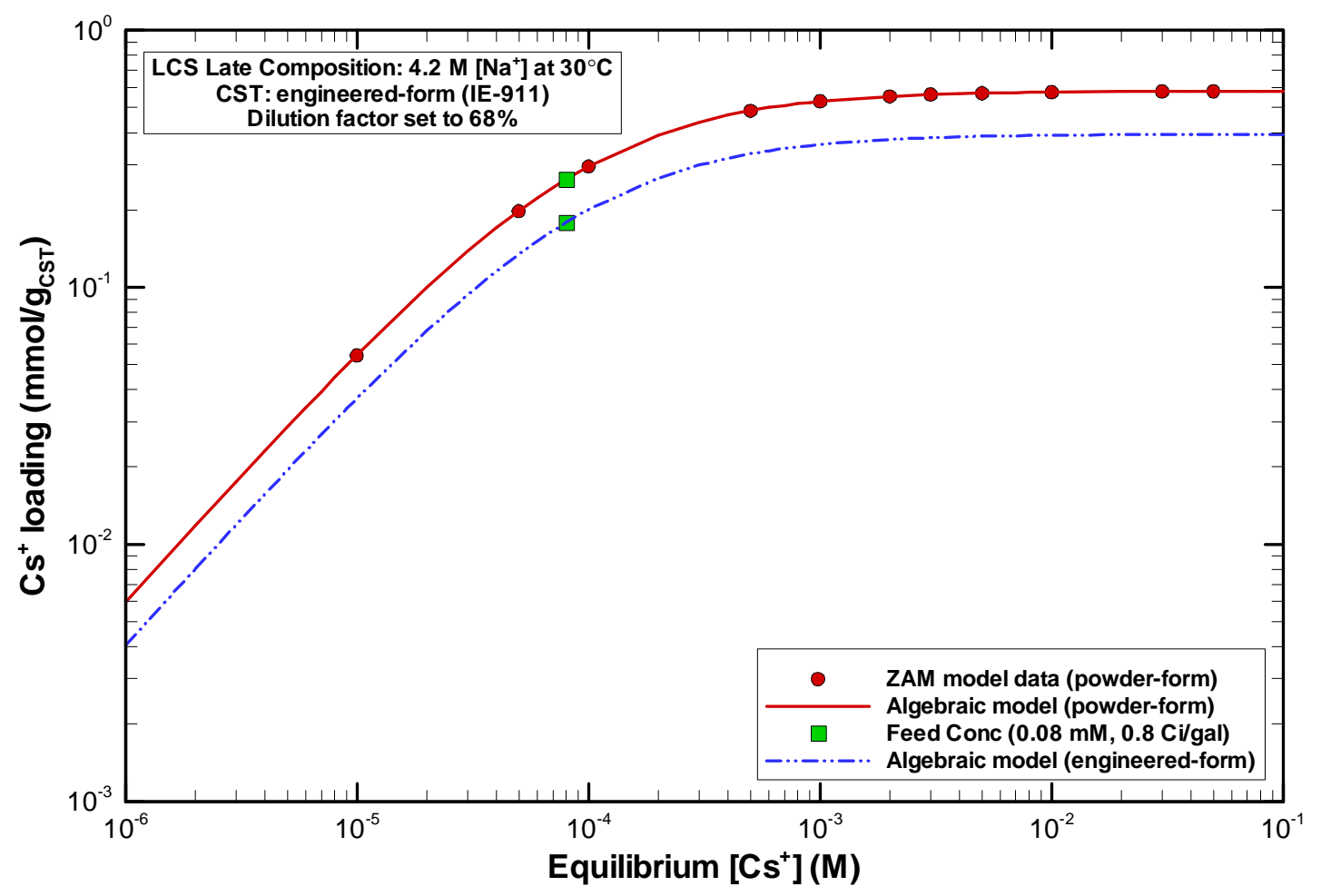

Figure 3. Cesium Isotherm for LCS Late Waste Solution at $30^{\circ} \mathrm{C}$.

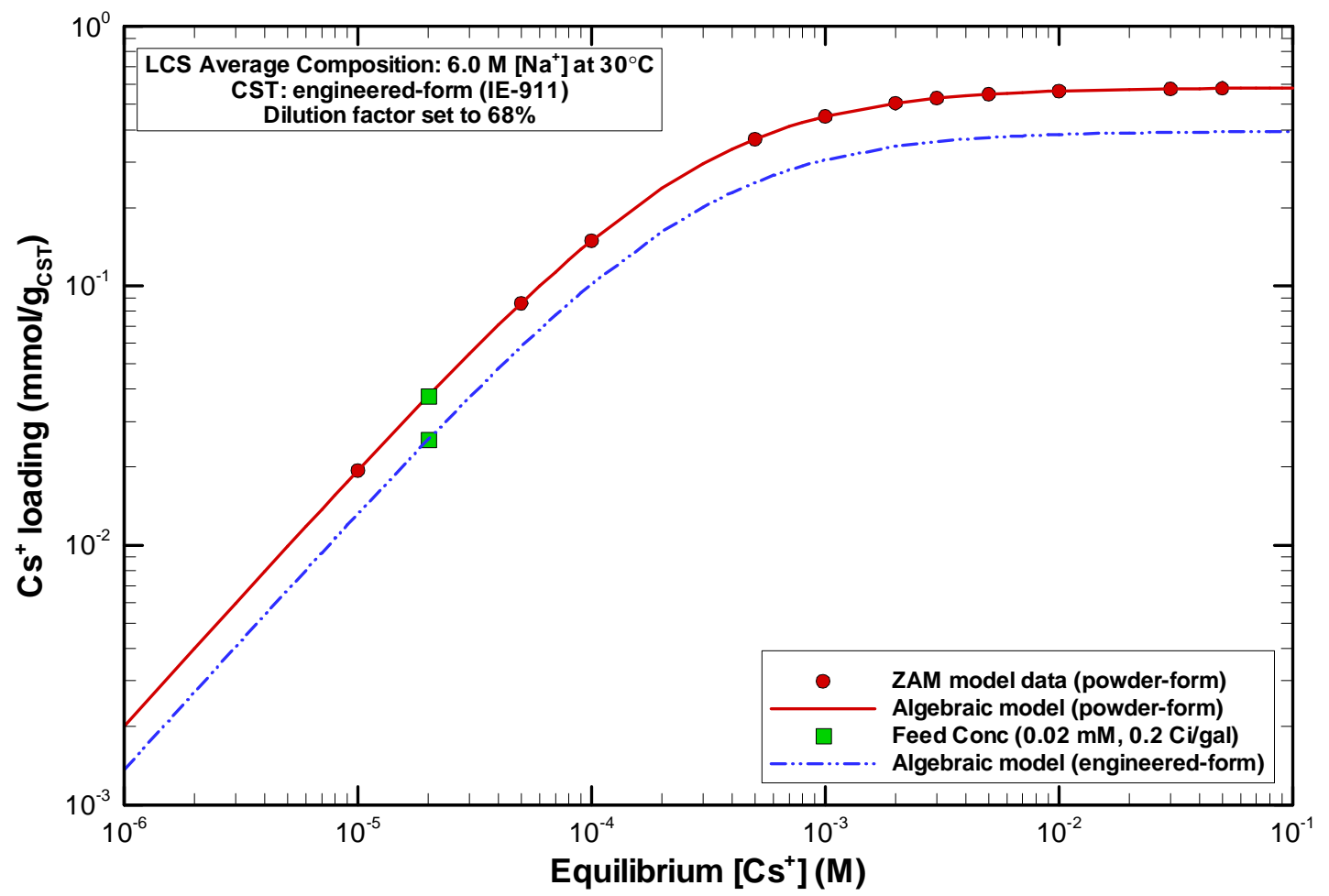

Figure 4. Cesium Isotherm for LCS Average Waste Solution at $30^{\circ} \mathrm{C}$. 


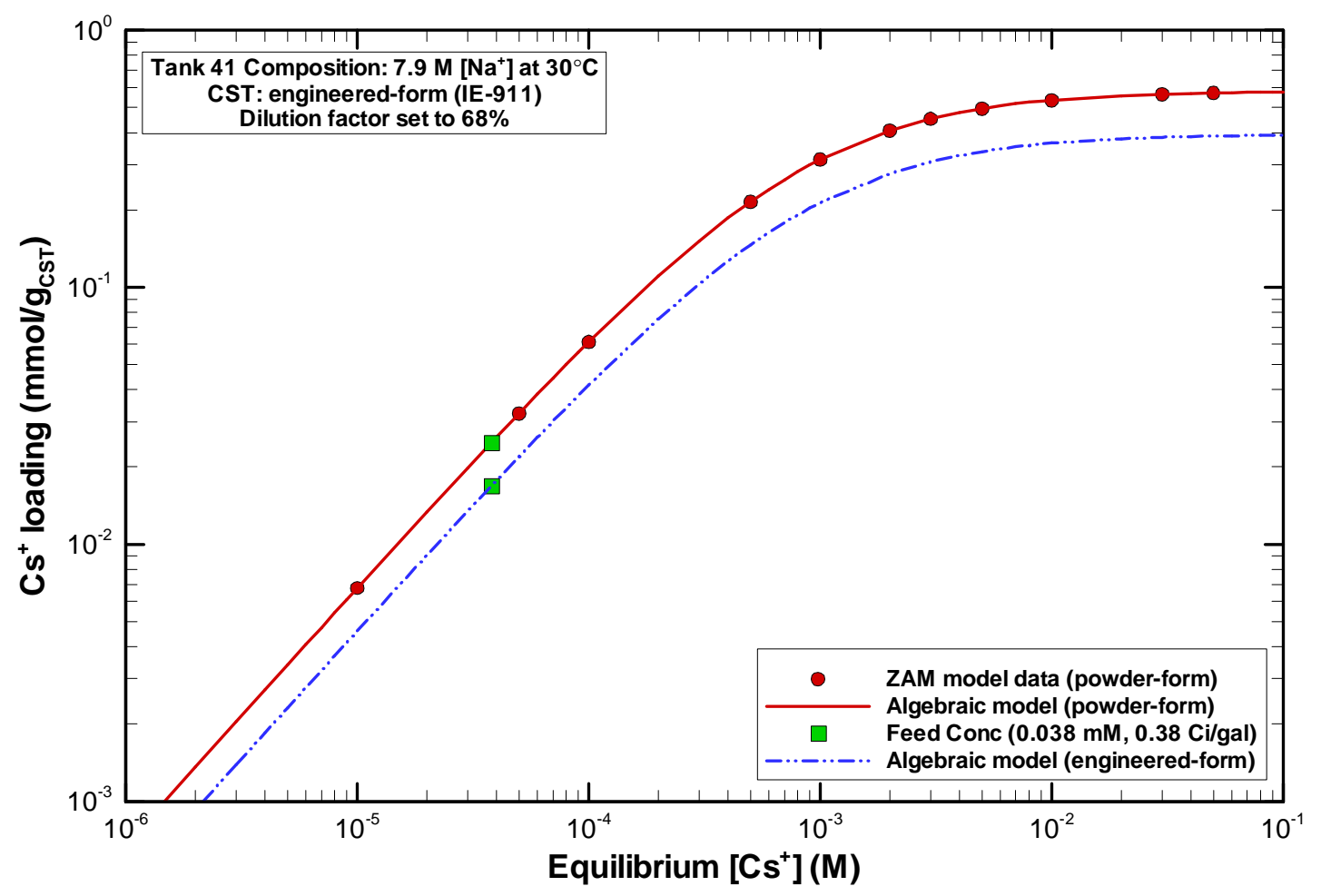

Figure 5. Cesium Isotherm for Recent Tank $41 \mathrm{H}$ Dissolved Salt Solution at $30^{\circ} \mathrm{C}$.

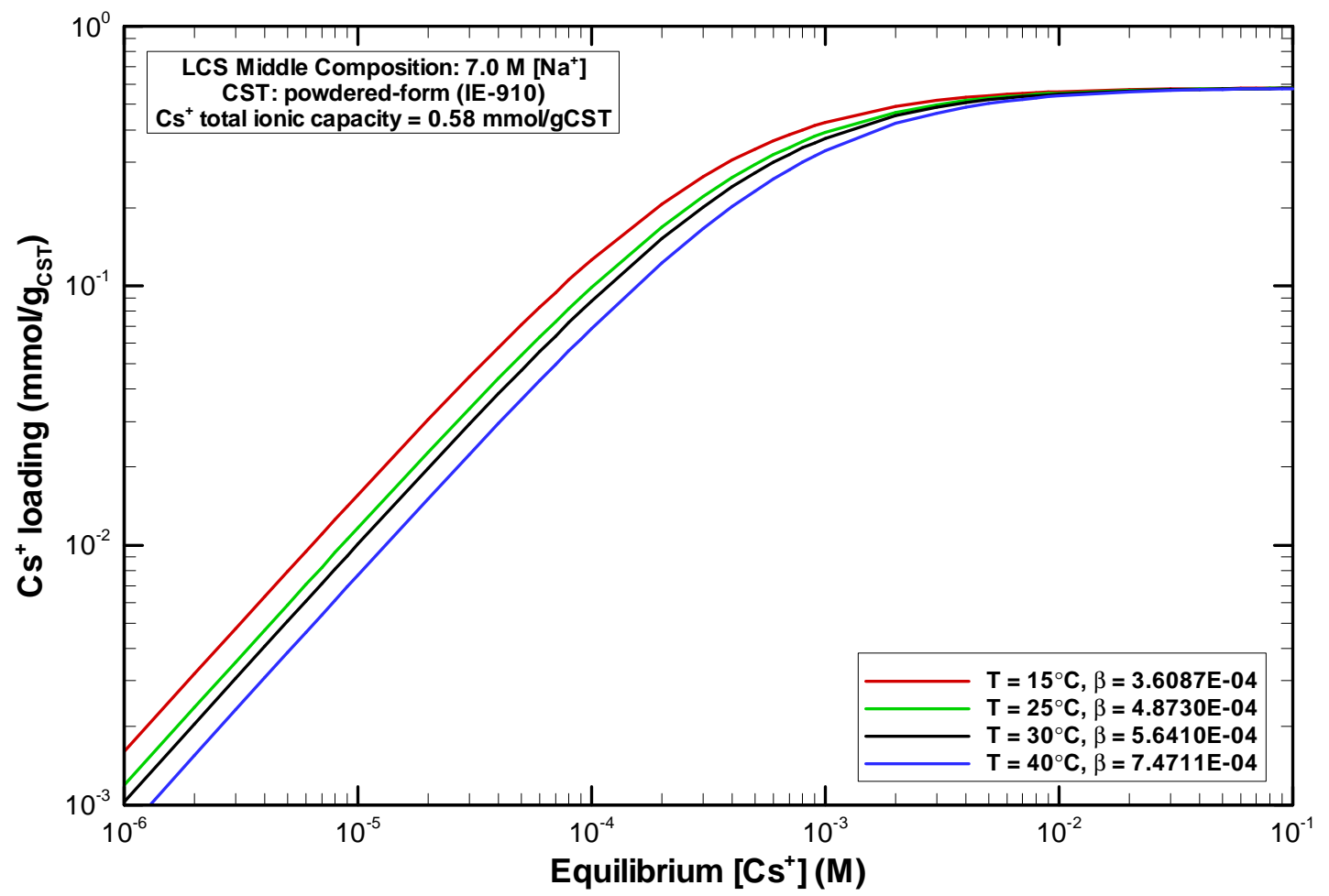

Figure 6. Cesium Isotherm for LCS Middle Waste Solution at 15, 25, 30 and $40{ }^{\circ} \mathrm{C}$. 
decreases with increasing liquid temperature at a given equilibrium cesium concentration. This trend is consistent with data from batch contact experiments.

\subsection{Cesium Isotherm for LCS Middle Waste Solution at Various Potassium Concentrations.}

Potassium is a primary competitor to cesium for CST IX sites. A series of ZAM isotherms were generated for the LCS Middle waste solution where the potassium concentration was altered about the nominal value of $7 \mathrm{mM}$. The altered potassium levels represent bounding values expected in the feed streams from the LCS waste tanks. Figure 7 shows the cesium isotherm for the LCS Middle waste solution with initial potassium concentrations of 2,7 and $15 \mathrm{mM}$ at $30^{\circ} \mathrm{C}$. The cesium isotherm demonstrates little change from nominal with potassium concentrations in the range of interest. The trend, though small, is better cesium loading with lower potassium concentrations (i.e., lower • values generate higher cesium loadings).

\subsection{Cesium Isotherm for LCS Middle Waste Solution at Various Hydroxide Concentrations.}

A series of ZAM isotherms were generated for the LCS Middle waste solution where the hydroxide concentration was altered about the nominal value of $1.0 \mathrm{M}$. The altered hydroxide levels represent bounding values expected in the feed streams from the LCS waste tanks. Figure 8 shows the cesium isotherm for the LCS Middle waste solution with hydroxide concentrations of $0.5,1.0$ and $2.6 \mathrm{M}$ at $30{ }^{\circ} \mathrm{C}$. The cesium isotherm exhibits enhanced cesium loading as the hydroxide concentration increases beyond 1.0 M to 2.6 M. Data from Zheng et al. (Zheng, 1996) shows a gradual increase in cesium distribution coefficient from acidic conditions to a hydroxide concentration of $0.1 \mathrm{M}$. Beyond a hydroxide concentration of $0.1 \mathrm{M}$, there is a drastic increase in the cesium distribution coefficient. The improved cesium loading with higher hydroxide concentration is consistent with Zheng's data (Zheng et al., 1996a).

\subsection{Cesium Isotherm for LCS Middle Waste Solution with Dilution and Concentration.}

The LCS Middle waste solution contains a nominal sodium concentration of $7 \mathrm{M}$. A series of ZAM isotherms were computed for a LCS Middle waste solution which potentially could be diluted to a sodium concentration of $6 \mathrm{M}$ or concentrated to a sodium concentration of $8 \mathrm{M}$. The LCS Middle waste solution cesium isotherm with dilution and concentration is given in Figure 9. There is a $\pm 14 \%$ change in sodium, hydroxide and potassium concentrations from the nominal values of 7.0, 1.0 and $0.007 \mathrm{M}$, respectively. Clearly, the change in sodium concentration provides the greatest impact on cesium loading overwhelming the benefit of a higher hydroxide level with a higher sodium level. 


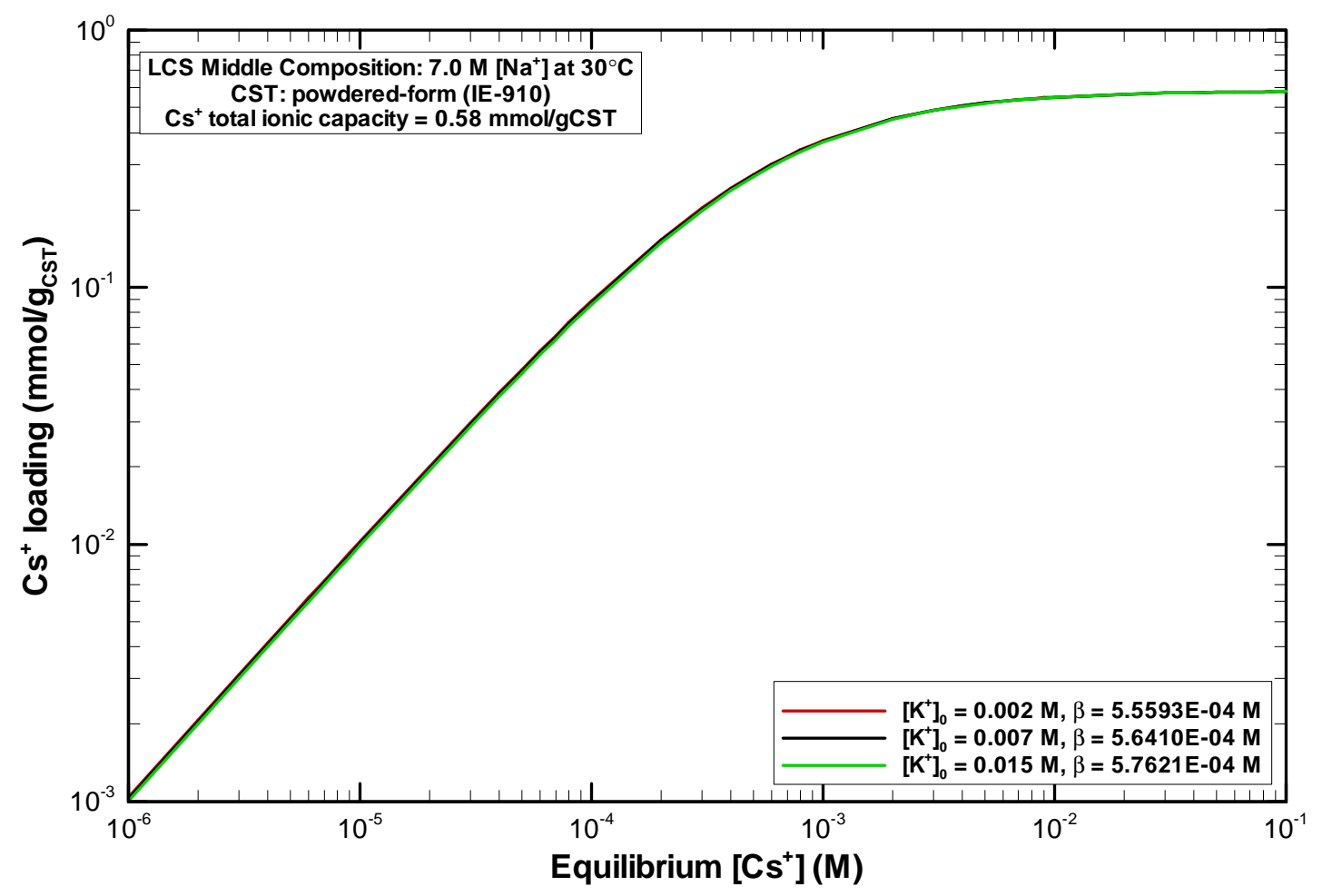

Figure 7. Cesium Isotherm for LCS Middle Waste Solution with Variation in Potassium Concentration at $30{ }^{\circ} \mathrm{C}$.

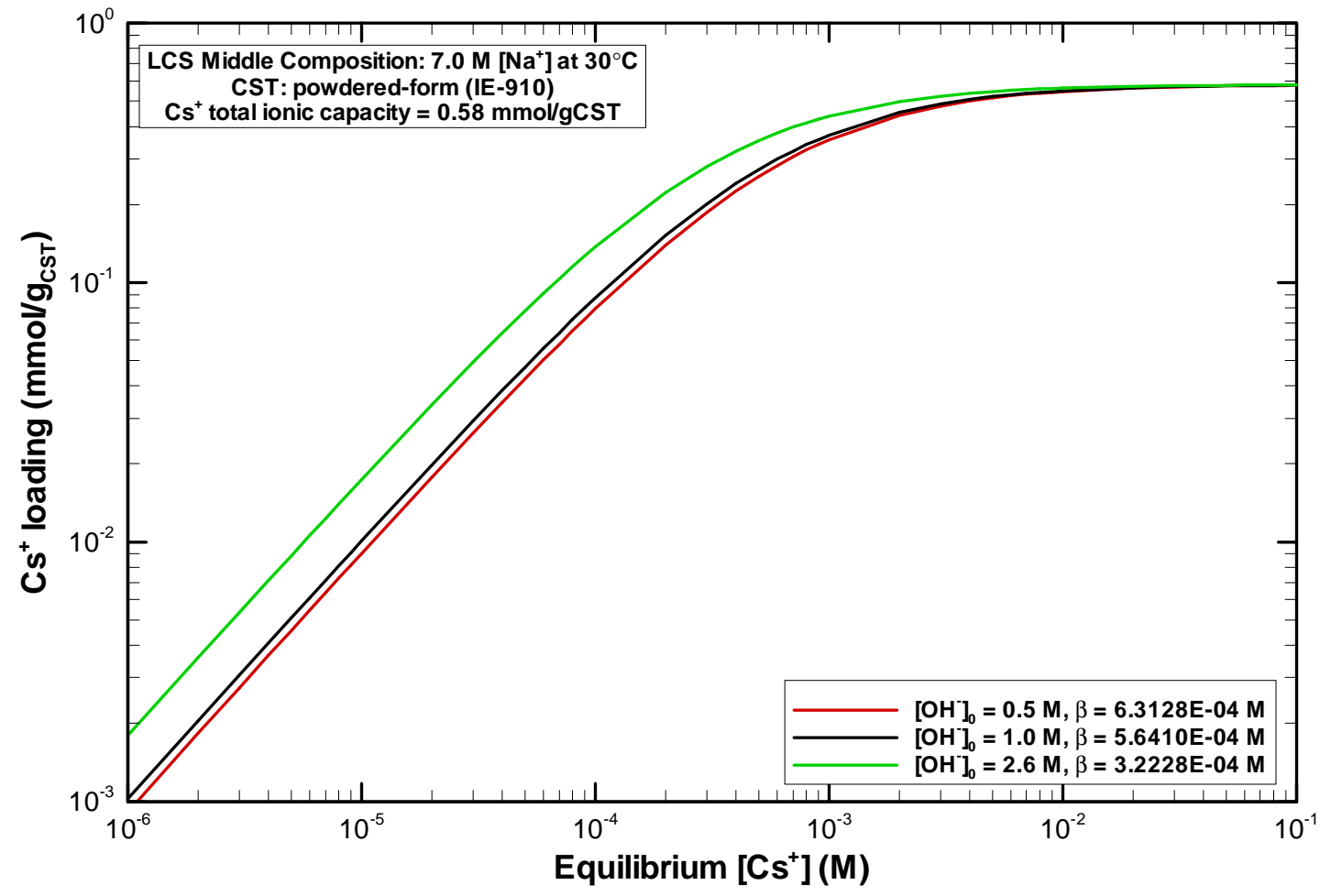

Figure 8. Cesium Isotherm for LCS Middle Salt Solution with Variation in Hydroxide Concentration at $30{ }^{\circ} \mathrm{C}$. 
Small Column Ion Exchange Analysis for Removal of Cesium from SRS

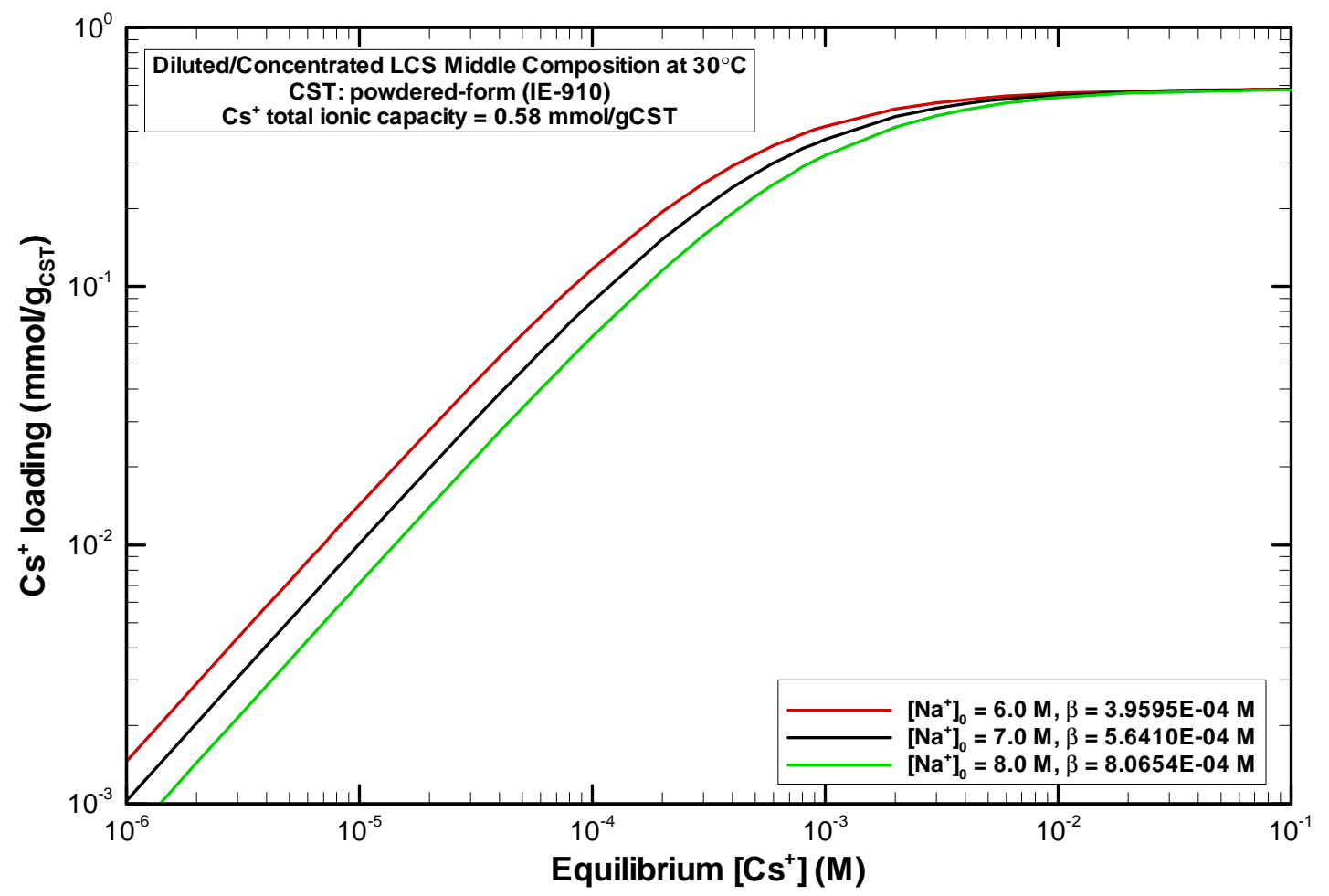

Figure 9. Cesium Isotherm for LCS Middle Salt Solution with Dilution to $\left[\mathrm{Na}^{+}\right]=6 \mathrm{M}$ and Concentration to $\left[\mathrm{Na}^{+}\right]=8 \mathrm{M}$ at $30{ }^{\circ} \mathrm{C}$. 


\subsection{ORNL Single Batch Contact Experiments}

A series of cesium loading tests were conducted by ORNL researchers (Taylor et al., 2003) using as-received CST in four LCS stimulant compositions. The batch contact tests were performed at a temperature of $25^{\circ} \mathrm{C}$ using $0.1 \mathrm{~g}$ of CST and $10 \mathrm{~mL}$ of simulant. The LCS simulants were prepared based on information from Darrel Walker of SRTC and reflect the compositions given in Table 5. The exception to the standard recipes is that the cesium concentrations were spiked to a value of $0.2 \mathrm{mM}$ for all the simulants. The sorbent tested was caustic washed Crystalline Silicotitanate (IONSIV $^{\circledR}$ IE-911-CW) from UOP, LLC (Des Plaines, IL). The CST samples tested were in sodium form (as-received).

A ZAM isotherm was generated for each of the LCS waste compositions at $25^{\circ} \mathrm{C}$. Each cesium loading curve (cesium CST solid loading versus final aqueous cesium concentration) was fitted to a 2-parameter single-component algebraic isotherm. A $68 \%$ dilution factor was applied to the algebraic ZAM isotherm to compute the algebraic isotherm for the engineered form of CST (IE911).

\subsection{Batch Contact Results}

Figures 10 through 13 show a comparison between the ORNL batch contact experiment and the corresponding algebraic isotherm for the LCS Early, Middle, Late and Average compositions, respectively. Samples 1 and 2 for each of the experiments exhibit excellent repeatability. The CST sorbent used was IONSIV ${ }^{\circledR}$ IE-911, yet the batch contact results fall very close to the ZAM isotherm for IE-910. One explanation is that the capacity of the IE-910 is higher now (higher solid density, 1.1 versus $1.0 \mathrm{~g} / \mathrm{ml}$ ). The $68 \%$ dilution factor will still be applied to the engineering form of CST (IE-911) for conservatism in the column runs per direction by the customer. 


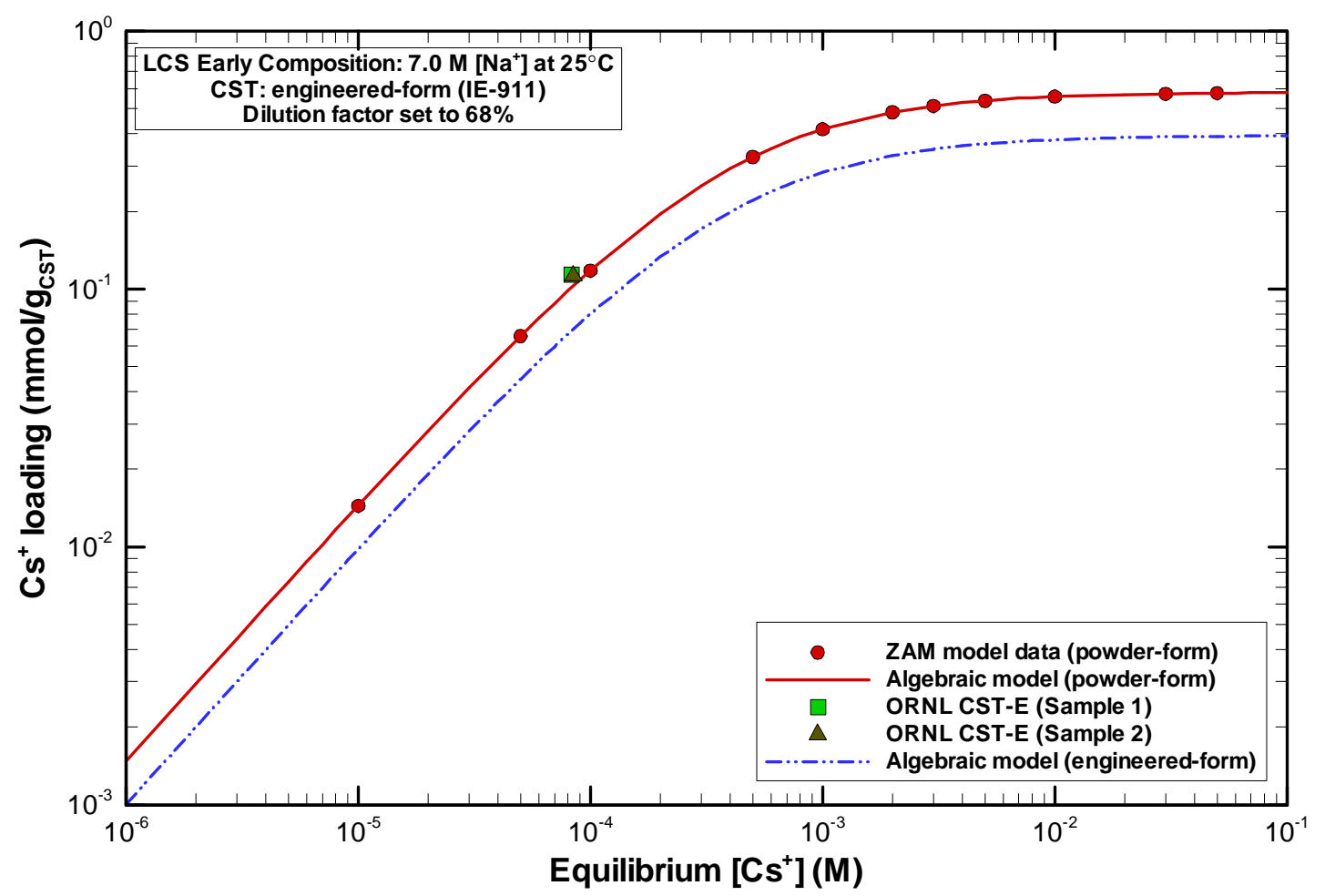

Figure 10. Comparison of ORNL Single Batch Contact Experiment to ZAM Isotherm for LCS Early Simulant at $25{ }^{\circ} \mathrm{C}$.

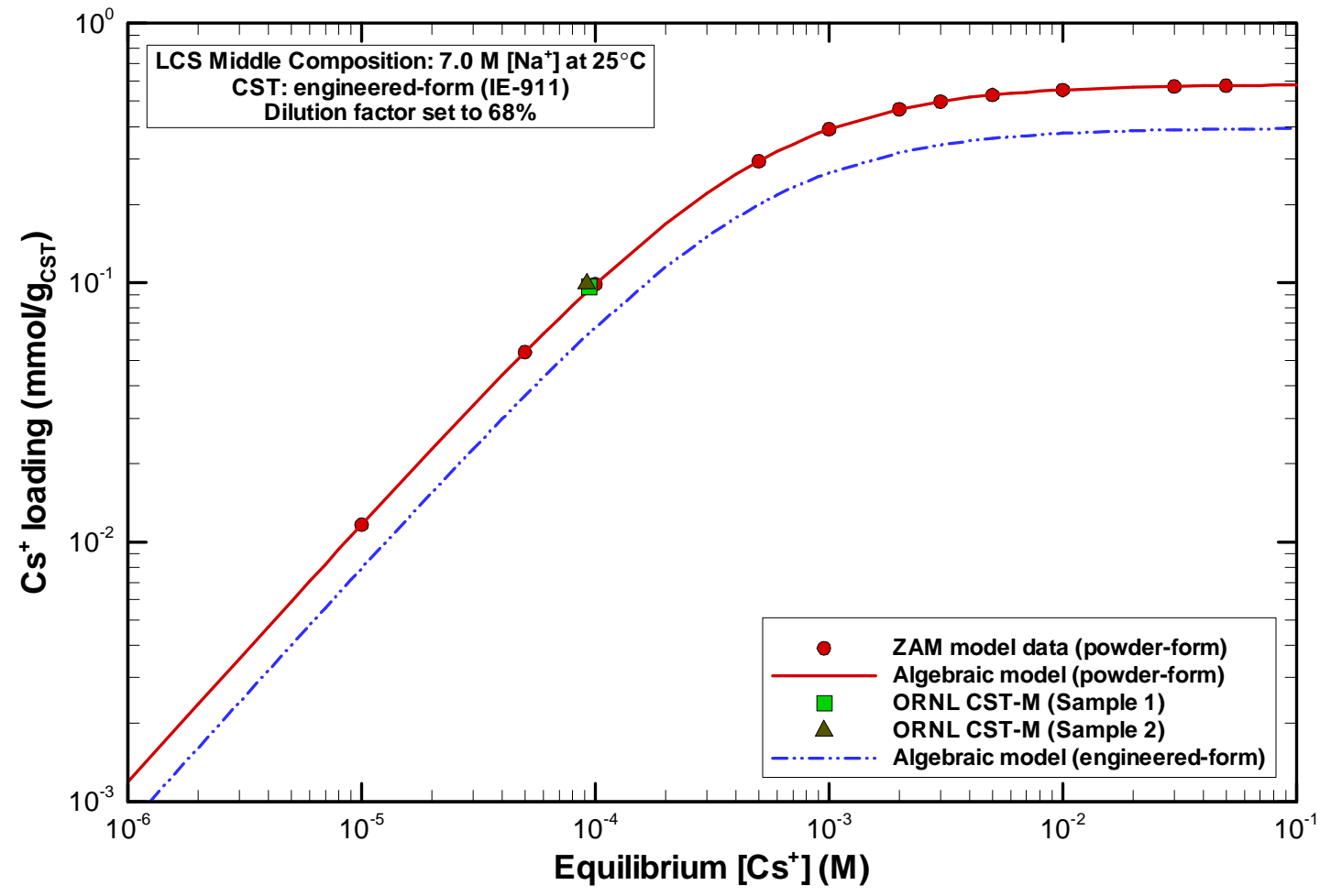

Figure 11. Comparison of ORNL Single Batch Contact Experiment to ZAM Isotherm for LCS Middle Simulant at $25^{\circ} \mathrm{C}$. 


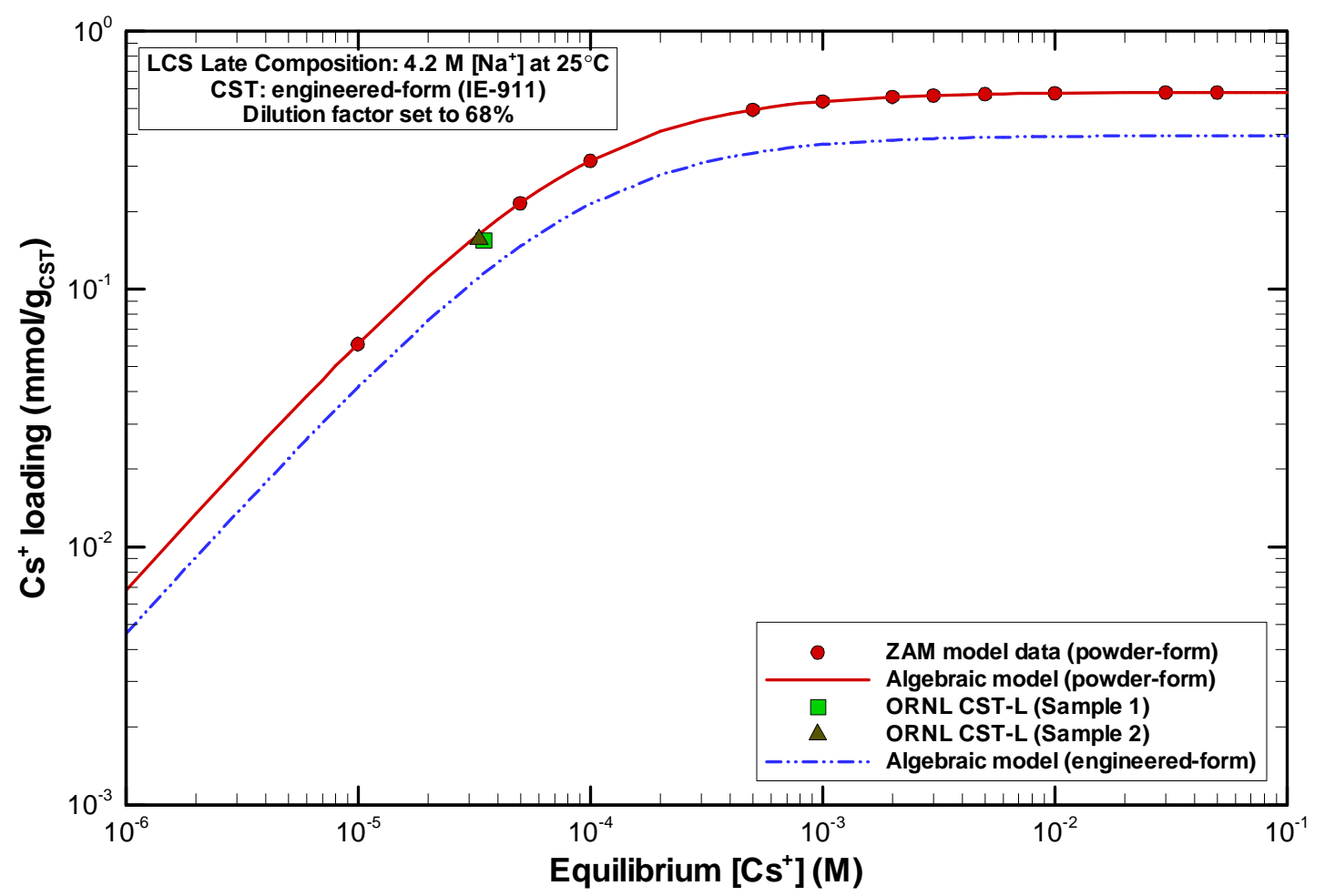

Figure 12. Comparison of ORNL Single Batch Contact Experiment to ZAM Isotherm for LCS Late Simulant at $25^{\circ} \mathrm{C}$.

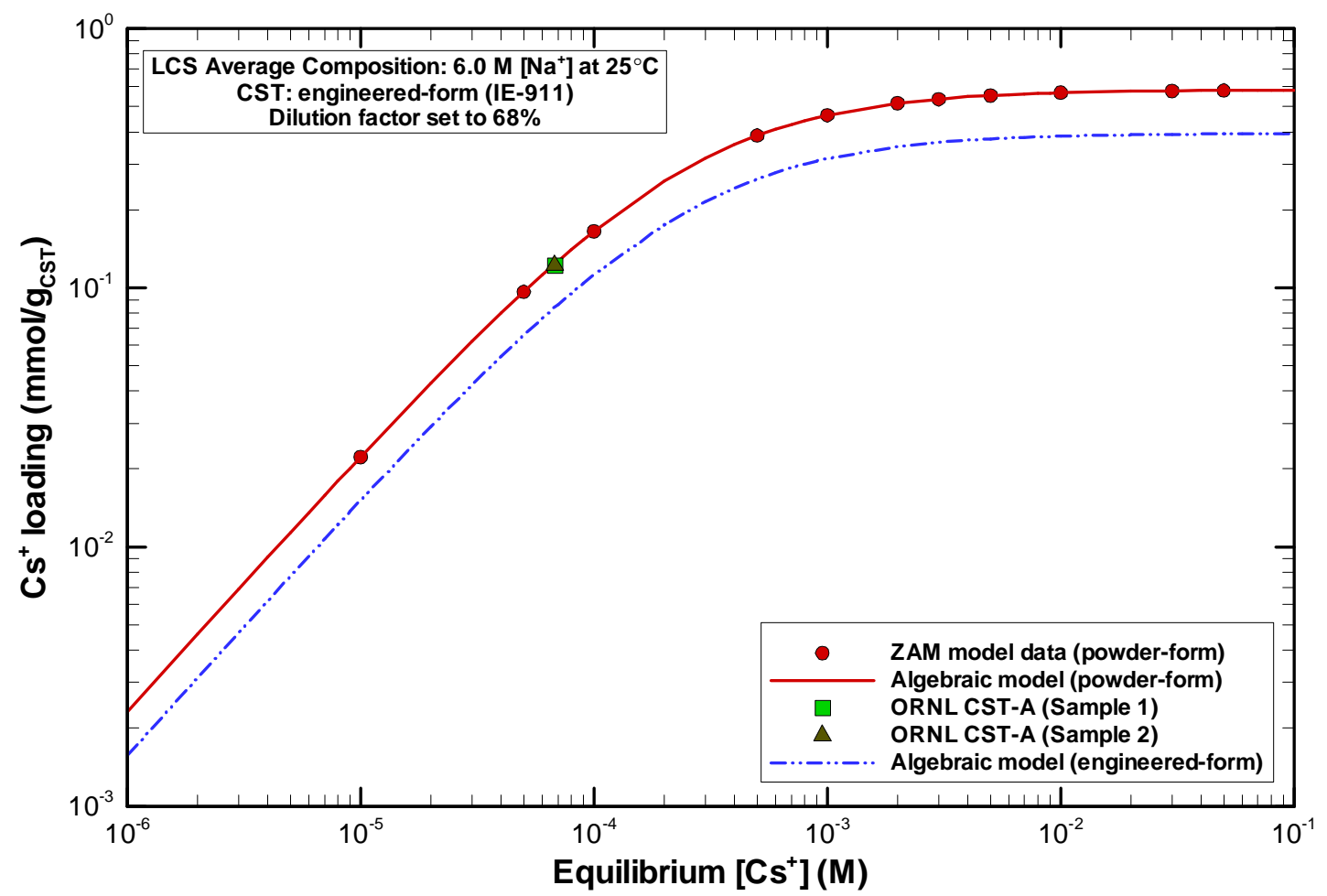

Figure 13. Comparison of ORNL Single Batch Contact Experiment to ZAM Isotherm for LCS Average Simulant at $25^{\circ} \mathrm{C}$. 


\subsection{Column Performance Modeling}

An ion exchange model predicted cesium loading performance for columns packed with IONSIV $^{\circledR}$ IE-911. The transport model includes axial dispersion, film diffusion, and pore diffusion within the IE-911 particles. The VERSE-LC computer code performs the calculations. Given column and operating parameters, the VERSE-LC code provides the cesium concentration in the column effluent as a function of the volume of waste processed referred to as a breakthrough curve.

We used two formats for plotting breakthrough curves, exit concentration and "bucket" average. The first format plots the instantaneous exit concentration of cesium leaving the column as a function of the volume of salt solution processed. The second format plots the volume average cesium concentration of the processed solution ("bucket" average). The first format fits a process controlled by a limiting value of the cesium concentration at the column exit. For example, if the product must contain less than $0.08 \mathrm{Ci}$ of $\mathrm{Cs}-137$ per gallon of processed waste, this control method stops processing when the instantaneous exit concentration equals the $0.08 \mathrm{Ci} / \mathrm{gal}$ limit. In this case, the entire batch of processed waste averages less than $0.08 \mathrm{Ci} /$ gal since only the final gallon equaled $0.08 \mathrm{Ci} /$ gal. An alternative process control strategy monitors the volume (mixture) average cesium concentration of the batch of waste passed through the column and ensures the batch average (or "bucket" average) does not exceed $0.08 \mathrm{Ci} /$ gal. This alternative allows processing more waste through a column and generates less loaded sorbent to be disposed of in the melter.

Table 6 summarizes the volume of waste processed for various tank feed solutions at a cesium breakthrough of $0.008 \mathrm{mM}$. Figures 14 through 22 show the instantaneous and bucket average cesium breakthrough curves.

Table 6. Volume of Waste Processed for Various Tank Feed Solutions at a Cesium Breakthrough of $0.008 \mathrm{mM}(0.08 \mathrm{Ci} / \mathrm{gal})$.

\begin{tabular}{|c|c|c|c|c|c|c|c|}
\hline $\begin{array}{c}\text { Scenario } \\
\text { No. }\end{array}$ & Figure & $\begin{array}{c}\text { Tank } \\
\text { Feed }\end{array}$ & $\begin{array}{c}\text { Composition } \\
\text { Variability }\end{array}$ & $\begin{array}{c}\text { Feed } \\
\text { Flow } \\
(\mathbf{g p m})\end{array}$ & $\begin{array}{c}\text { Feed } \\
\text { Temp } \\
(\mathbf{C})\end{array}$ & $\begin{array}{c}\text { Vol } \\
\text { Processed } \\
\text { Exit } \\
(\mathbf{k g a l})\end{array}$ & $\begin{array}{c}\text { Vol } \\
\text { Processed } \\
\text { Bucket } \\
\text { (kgal) }\end{array}$ \\
\hline 1 & 14 & LCS Early & Nominal & 25 & 30 & 134 & 227 \\
\hline 2 & 14 & LCS Middle & Nominal & 25 & 30 & 117 & 195 \\
\hline 3 & 14 & LCS Late & Nominal & 25 & 30 & 591 & 905 \\
\hline 4 & 14 & LCS Average & Nominal & 25 & 30 & 449 & 887 \\
\hline 5 & 15 & Tank 41H & Nominal & 25 & 30 & 102 & 188 \\
\hline 6 & 16 & LCS Middle & Nominal & 8 & 30 & 180 & 263 \\
\hline 7 & 16 & LCS Middle & Nominal & 20 & 30 & 131 & 212 \\
\hline 8 & 16 & LCS Middle & Nominal & 30 & 30 & 106 & 180 \\
\hline 9 & 16 & LCS Middle & Nominal & 40 & 30 & 89 & 155 \\
\hline
\end{tabular}


Small Column Ion Exchange Analysis for Removal of Cesium from SRS

\begin{tabular}{|c|c|c|c|c|c|c|c|}
\hline $\begin{array}{c}\text { Scenario } \\
\text { No. }\end{array}$ & Figure & $\begin{array}{c}\text { Tank } \\
\text { Feed }\end{array}$ & $\begin{array}{c}\text { Composition } \\
\text { Variability }\end{array}$ & $\begin{array}{c}\text { Feed } \\
\text { Flow } \\
(\mathbf{g p m})\end{array}$ & $\begin{array}{c}\text { Feed } \\
\text { Temp } \\
(\mathbf{C})\end{array}$ & $\begin{array}{c}\text { Vol } \\
\text { Processed } \\
\text { Exit } \\
\text { (kgal) }\end{array}$ & $\begin{array}{c}\text { Vol } \\
\text { Processed } \\
\text { Bucket } \\
\text { (kgal) }\end{array}$ \\
\hline 10 & 17 & LCS Middle & Nominal & 25 & 15 & 173 & 288 \\
\hline 11 & 17 & LCS Middle & Nominal & 25 & 40 & 91 & 152 \\
\hline 12 & 18 & LCS Middle & Low Cs+ & 25 & 30 & 227 & 458 \\
\hline 13 & 18 & LCS Middle & High Cs+ & 25 & 30 & 85 & 131 \\
\hline 14 & 19 & LCS Middle & Low K+ & 25 & 30 & 119 & 198 \\
\hline 15 & 19 & LCS Middle & High K+ & 25 & 30 & 115 & 191 \\
\hline 16 & 20 & LCS Middle & Low OH- & 25 & 30 & 107 & 177 \\
\hline 17 & 20 & LCS Middle & High OH- & 25 & 30 & 189 & 315 \\
\hline 18 & 21 & LCS Middle & Diluted & 25 & 30 & 178 & 297 \\
\hline 19 & 21 & LCS Middle & Concentrated & 25 & 30 & 76 & 127 \\
\hline 20 & 22 & LCS Middle & Nominal & 25 & 30 & 65 & 112 \\
\hline 21 & 22 & LCS Middle & Nominal & 25 & 30 & 61 & 107 \\
\hline
\end{tabular}

Figure 14 shows cesium breakthrough curves for the LCS Early, Middle, Late and Average waste compositions. The order of breakthrough (first to last), from LCS Middle to LCS Late, is consistent with the cesium isotherms shown in Figures 2 to 5. The LCS Middle cesium isotherm has the lowest cesium loading for a given aqueous cesium concentration and the LCS Late cesium isotherm has the highest cesium loading. The waste volume processed can be determined for any decontamination factor desired. For example, assuming a product limit of $0.08 \mathrm{Ci} / \mathrm{gal}$, requires a decontamination factor (DF) of 10 for LCS Early, Middle, and Late waste solutions and a cesium breakthrough value of $0.008 \mathrm{mM}$. The LCS Average waste composition requires a DF of 2.5 to meet the product limit of $0.08 \mathrm{Ci} / \mathrm{gal}$. From the curves in Figure 14, a 432-gal column with LCS Early, Middle, Late and Average waste compositions will process 227,000, 195,000, 905,000 and 887,000 gallons, respectively at a bucket average cesium breakthrough of $0.008 \mathrm{mM}(0.08$ $\mathrm{Ci} / \mathrm{gal})$.

Figure 15 provides the cesium breakthrough curves for a recent Tank $41 \mathrm{H}$ dissolved salt solution. The Tank $41 \mathrm{H}$ dissolved salt solution cesium isotherm (Figure 5) has a slightly lower cesium loading, for a given aqueous cesium concentration (below saturation), than the LCS Middle cesium isotherm (Figure 2). Therefore, the cesium breakthrough occurs before that of the LCS Middle waste composition. The volume of waste processed based on an exit and bucket average cesium concentration of $0.008 \mathrm{mM}$ is 102,000 and 188,000 gallons, respectively.

Figure 16 shows the effect of flow rate on cesium breakthrough for the LCS Middle waste solution. Breakthrough occurs later (i.e., more waste is processed) as the flow rate decreases. A higher superficial velocity or flow rate increases axial dispersion which makes the 
WESTINGHOUSE SAVANNAH RIVER COMPANY

Small Column Ion Exchange Analysis for Removal of Cesium from SRS Low Curie Salt Solution Using Crystalline Silicotitanate (CST) Resin
Report:

WSRC-TR-2003-00430

Revision (Date):

$0(12 / 03)$

Page:

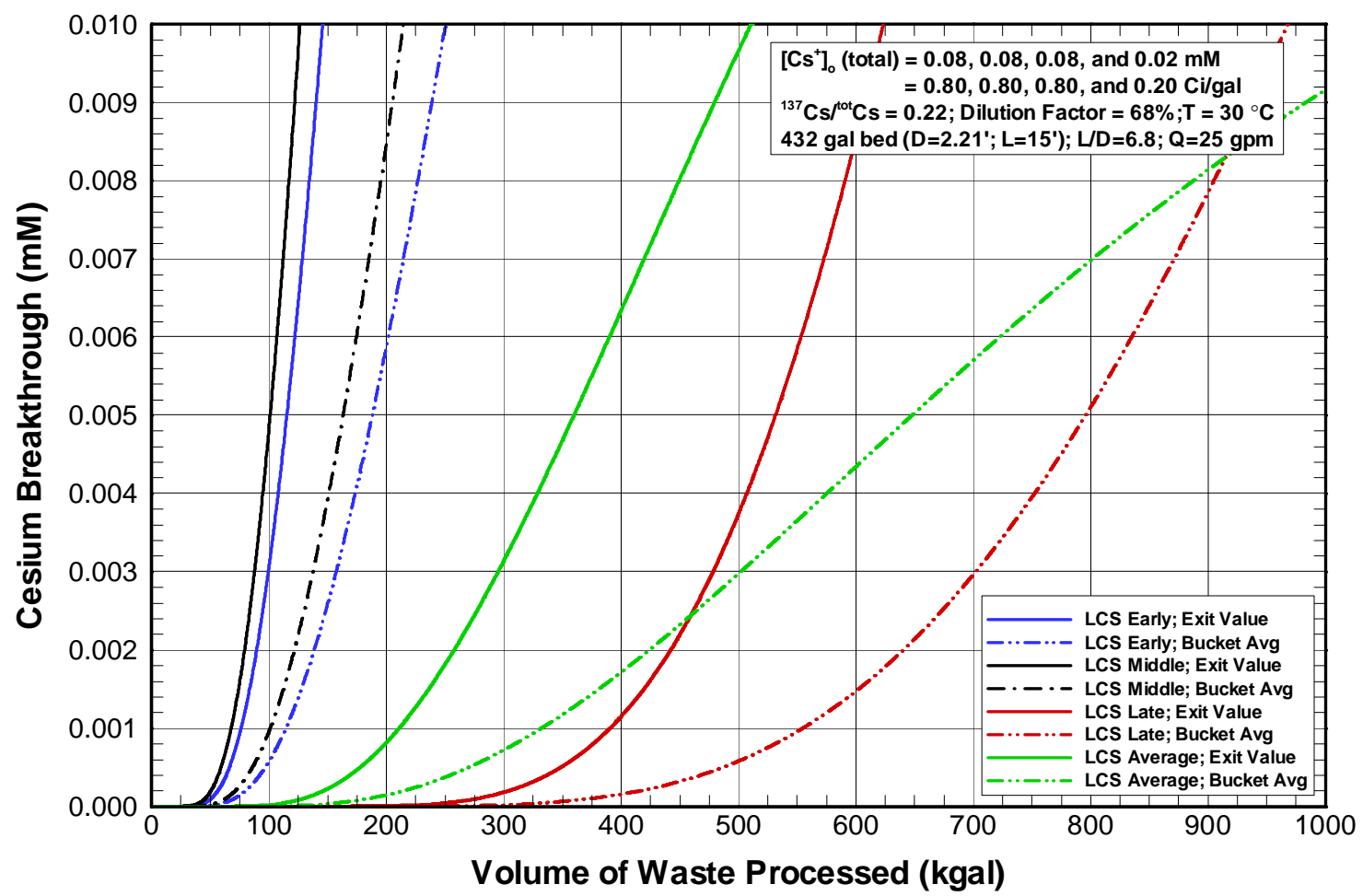

Figure 14. Cesium Breakthrough Curves for LCS Early, Middle, Late and Average Salt Solutions at $30{ }^{\circ} \mathrm{C}$.

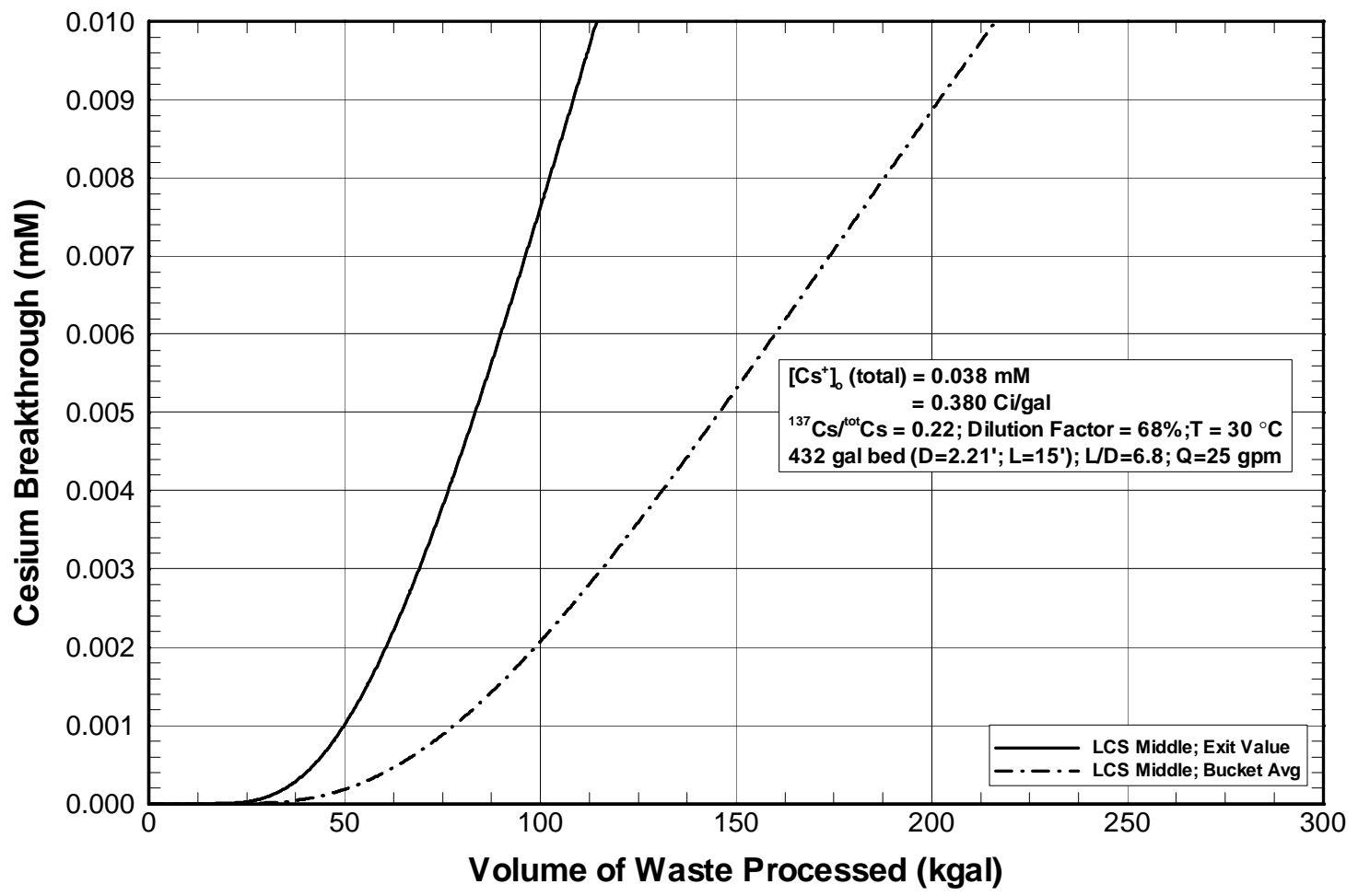

Figure 15. Cesium Breakthrough Curves for Recent Tank 41H Dissolved Salt Solution at $30{ }^{\circ} \mathrm{C}$. 


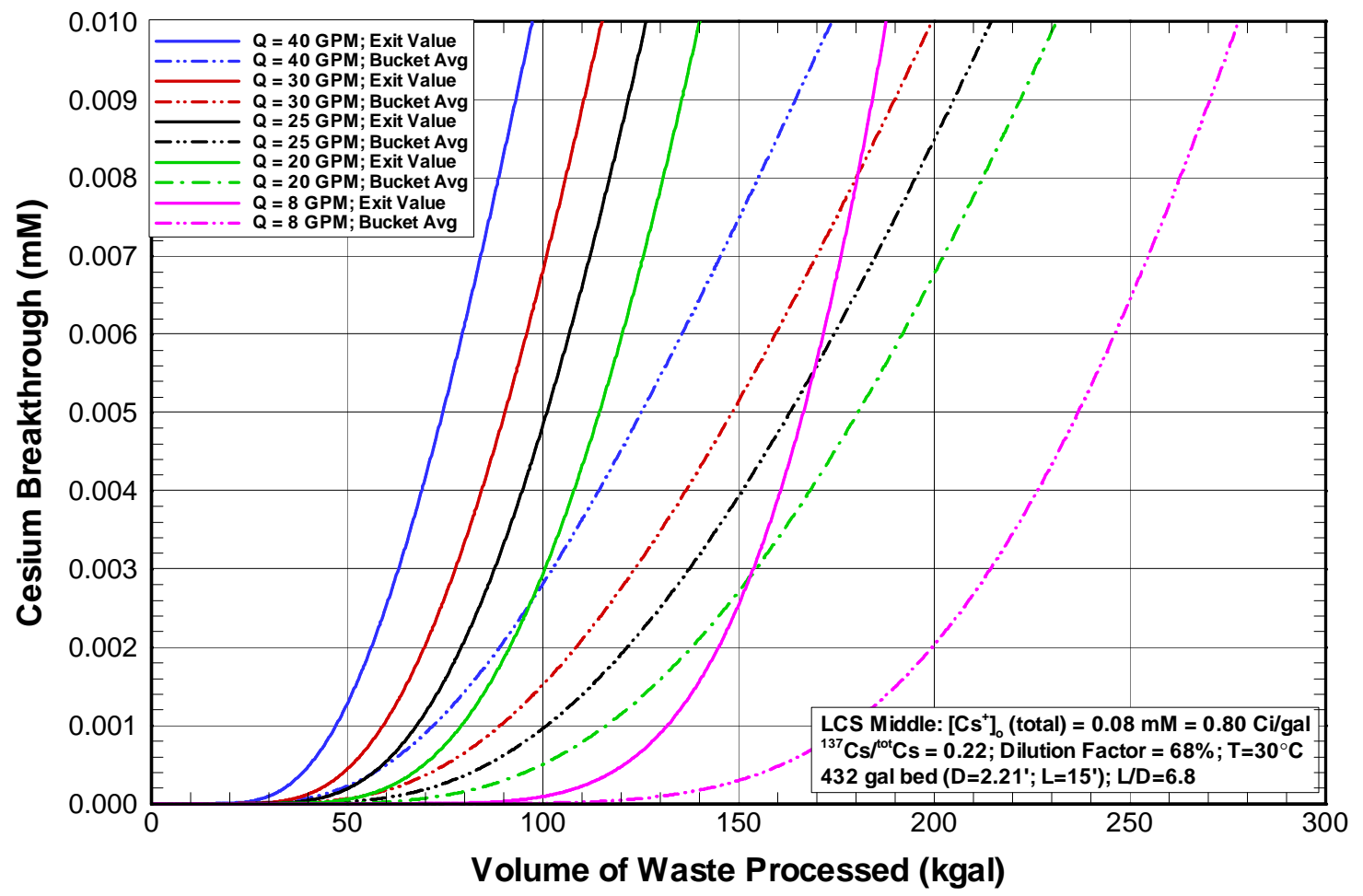

Figure 16. Cesium Breakthrough Curves for LCS Middle Salt Solution Flowing at 8, 20 25, 30 and $40 \mathrm{gpm}$.

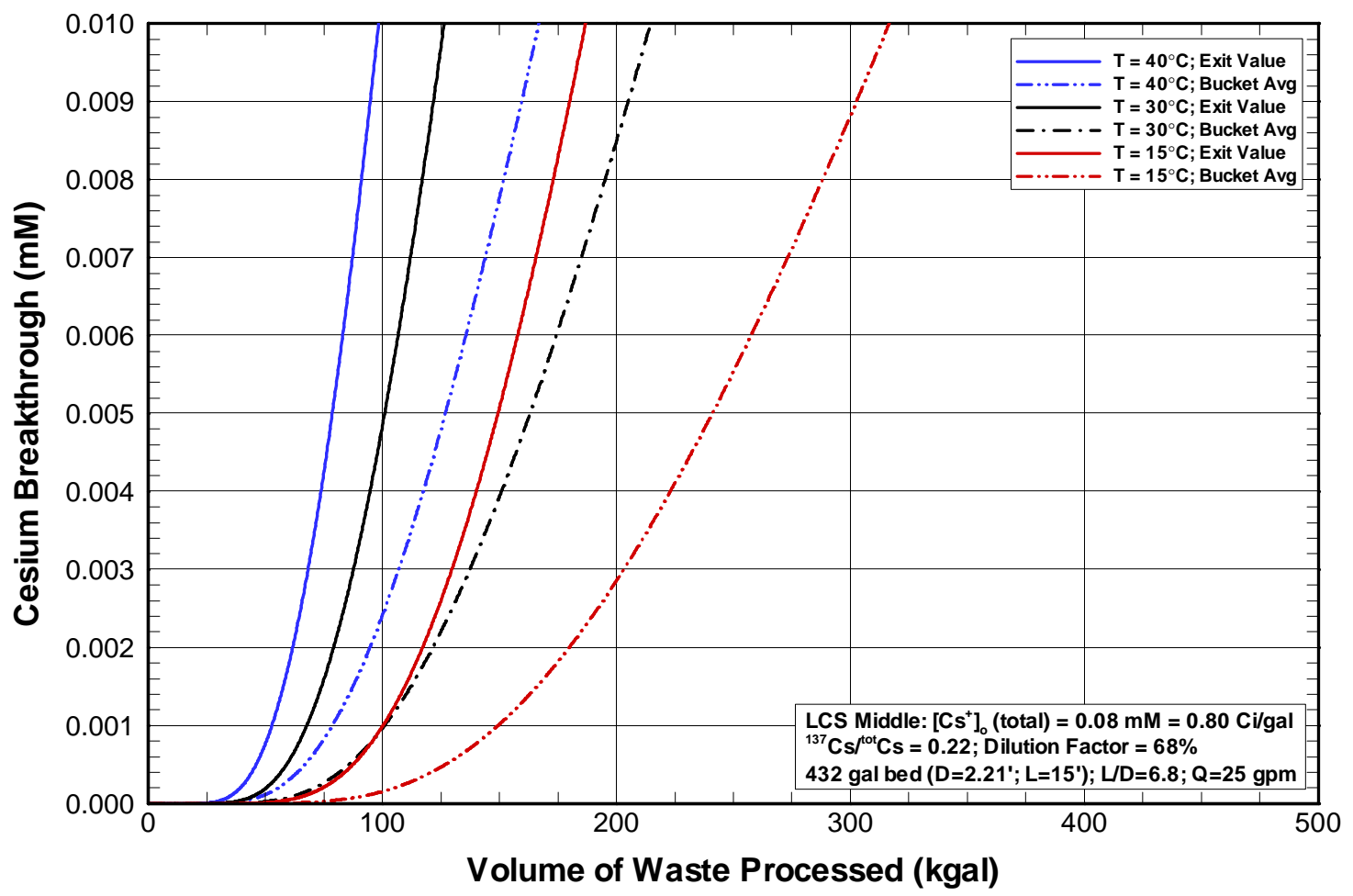

Figure 17. Cesium Breakthrough Curves for LCS Middle Salt Solution at 15, 30 and 40 ${ }^{\circ} \mathrm{C}$. 
chromatographic wave through the column more S-shaped leading to earlier breakthrough. A slower superficial velocity or flow rate increases mass transfer limiting pore diffusion leading to later breakthrough. At the bucket average cesium breakthrough of $0.008 \mathrm{mM}$, decreasing the flow rate from a nominal 25 to $8 \mathrm{gpm}$ allows processing $35 \%$ more waste. Increasing the feed flow rate from 25 to $40 \mathrm{gpm}$ allows processing $20 \%$ less waste.

Figure 17 shows the effect of feed temperature on cesium breakthrough for the LCS Middle waste solution. Breakthrough occurs later as the feed temperature decreases due to higher cesium loading along the column. The cesium loading monotonically increases with decreasing temperature as shown by the cesium isotherm in Figure 6. At the bucket average cesium breakthrough of $0.008 \mathrm{mM}$, chilling the feed temperature from a nominal 30 to $15{ }^{\circ} \mathrm{C}$ allows processing $48 \%$ more waste. Increasing the feed temperature from 30 to $40{ }^{\circ} \mathrm{C}$ allows processing $22 \%$ less waste.

Figure 18 shows the cesium breakthrough curves for LCS Middle waste solution with cesium concentrations of $0.20,0.08$ and $0.02 \mathrm{mM}(2.0,0.8$ and $0.2 \mathrm{Ci} / \mathrm{gal}$, respectively). A 10-fold increase in initial cesium concentration $(0.02$ to $0.20 \mathrm{mM})$ greatly reduces the volume processed. For example, at the bucket average cesium breakthrough of $0.008 \mathrm{mM}$, the reduction is $71 \%$ (458,000 gal vs. 131,000 gal).

Figure 19 shows the cesium breakthrough curves for LCS Middle waste solution with potassium concentrations of 15,7 and $2 \mathrm{mM}$. Potassium is an ion exchange competitor to cesium. The cesium isotherms (Figure 7) are practically identical for the LCS waste solution with the above variation in potassium concentration. Therefore, the cesium breakthrough occurs at about the same time.

Figure 20 contains cesium breakthrough curves where the hydroxide concentration has been changed about the nominal value of $1.0 \mathrm{M}$. The higher hydroxide concentration of $2.6 \mathrm{M}$ increases the cesium loading as shown by the cesium isotherm in Figure 8. At the lower hydroxide concentration of $0.5 \mathrm{M}$, there is a small reduction in cesium loading from the nominal cesium isotherm. Cesium breakthrough occurs first with the least favorable isotherm, $[\mathrm{OH}-]=0.5$ $\mathrm{M}$, and last with most favorable isotherm $[\mathrm{OH}-]=2.6 \mathrm{M}$. The volume of waste processed for hydroxide concentrations of $0.5 \mathrm{M}, 1.0 \mathrm{M}$ and $2.6 \mathrm{M}$ is 177,000, 195,000 and 315,000 gallons, respectively.

Figure 21 shows cesium breakthrough curves for the LCS Middle waste solution diluted to a sodium concentration of $6 \mathrm{M}$ and concentrated to $8 \mathrm{M}$. Since all ion exchange competitors are being diluted or concentrated from their nominal values, we must look at the cesium isotherm to assess the performance of the column. The cesium loading for a given aqueous cesium concentration decreases from the diluted to the concentrated LCS Middle waste composition. Therefore, breakthrough occurs first for the concentrated solution and last for the diluted solution. The volume of waste processed, at the bucket average cesium breakthrough of 0.008 $\mathrm{mM}$, for the diluted, nominal and concentrated LCS Middle solution is 297,000, 195,000 and 127,000 gallons, respectively. 


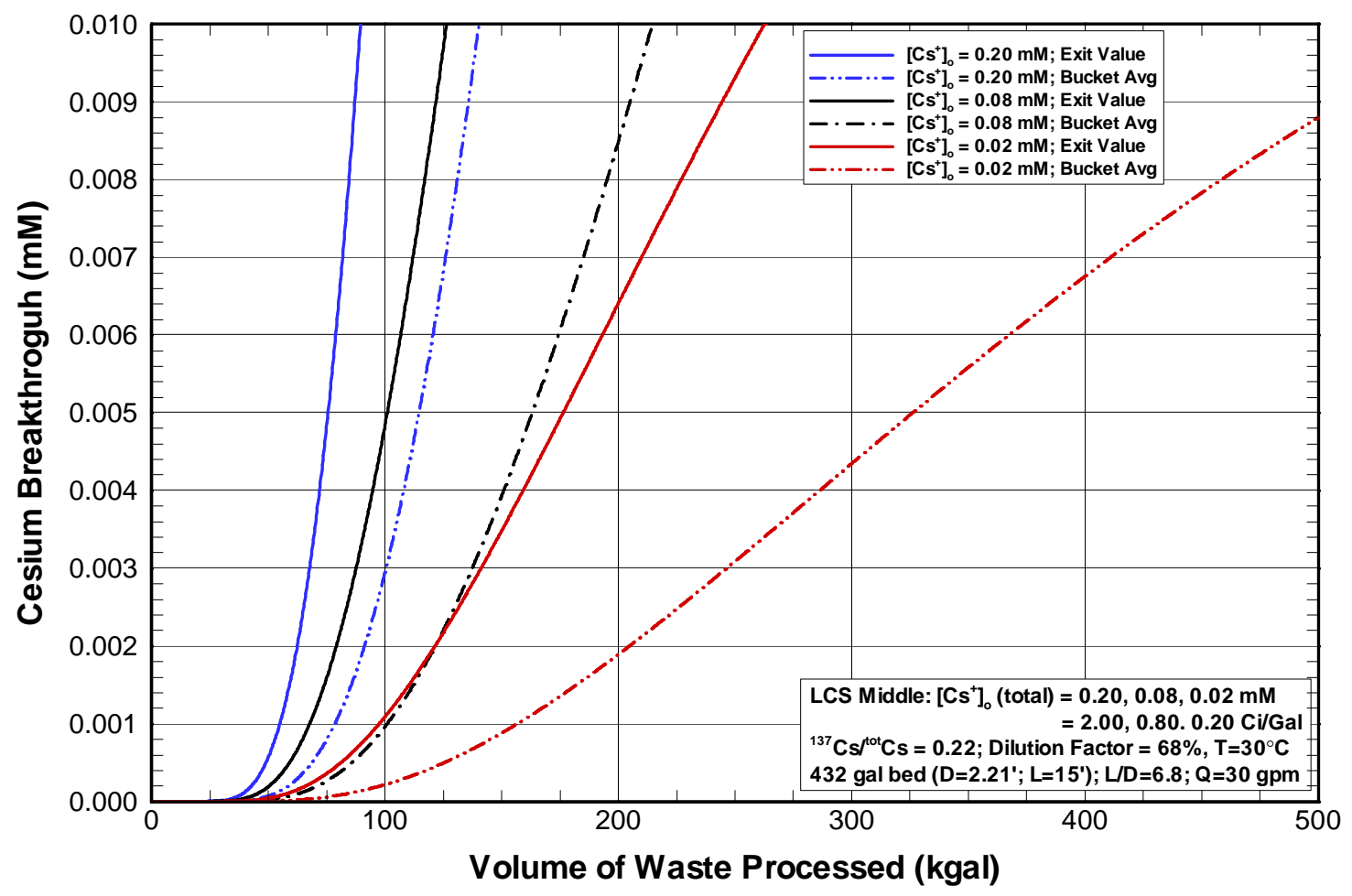

Figure 18. Cesium Breakthrough Curves for LCS Middle Waste Solution with Cesium Concentrations of $0.20,0.08$ and $0.02 \mathrm{mM}$.

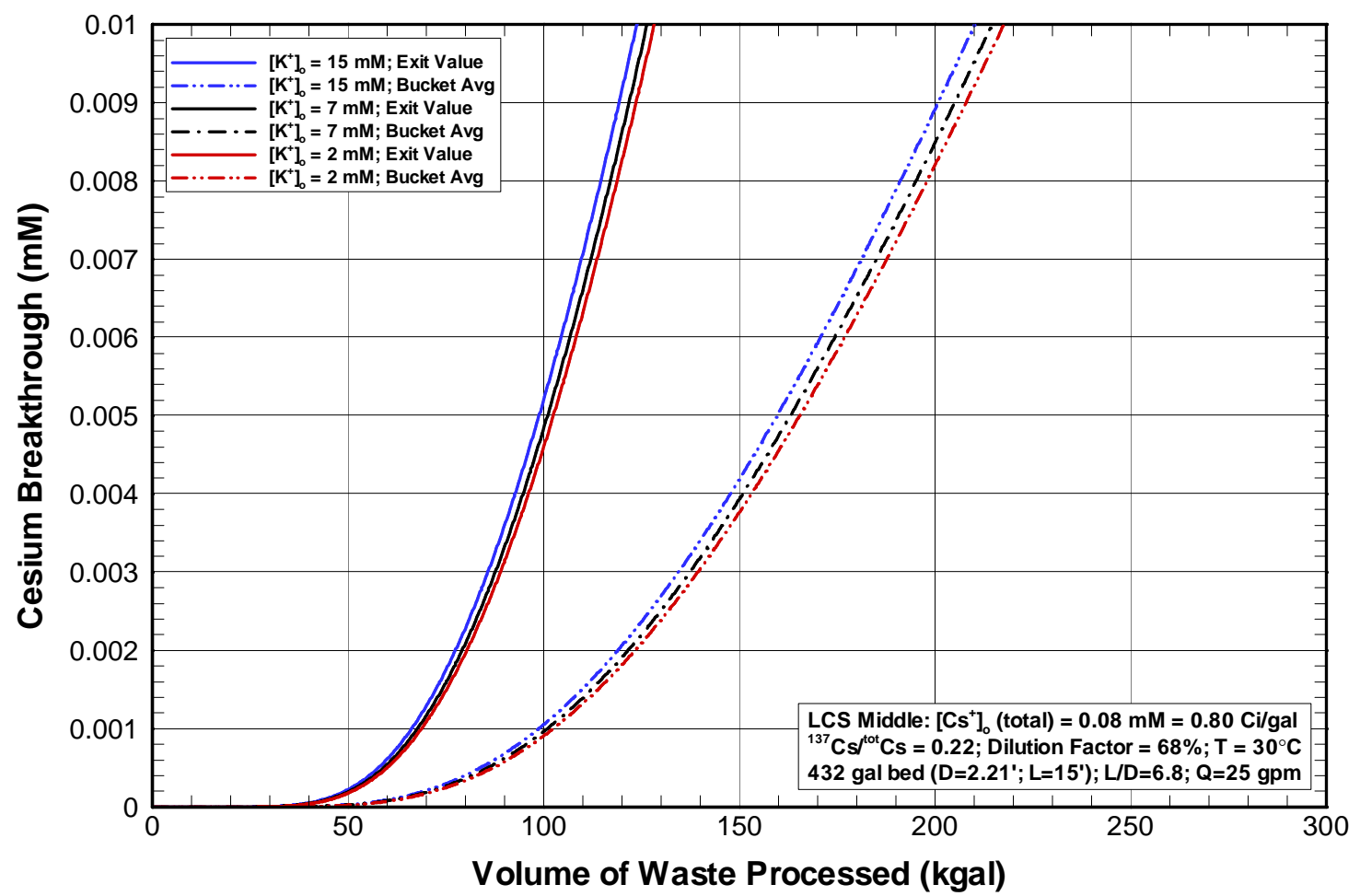

Figure 19. Cesium Breakthrough Curves for LCS Middle Waste Solution with Potassium Concentrations of 15, 7 and $2 \mathrm{mM}$. 


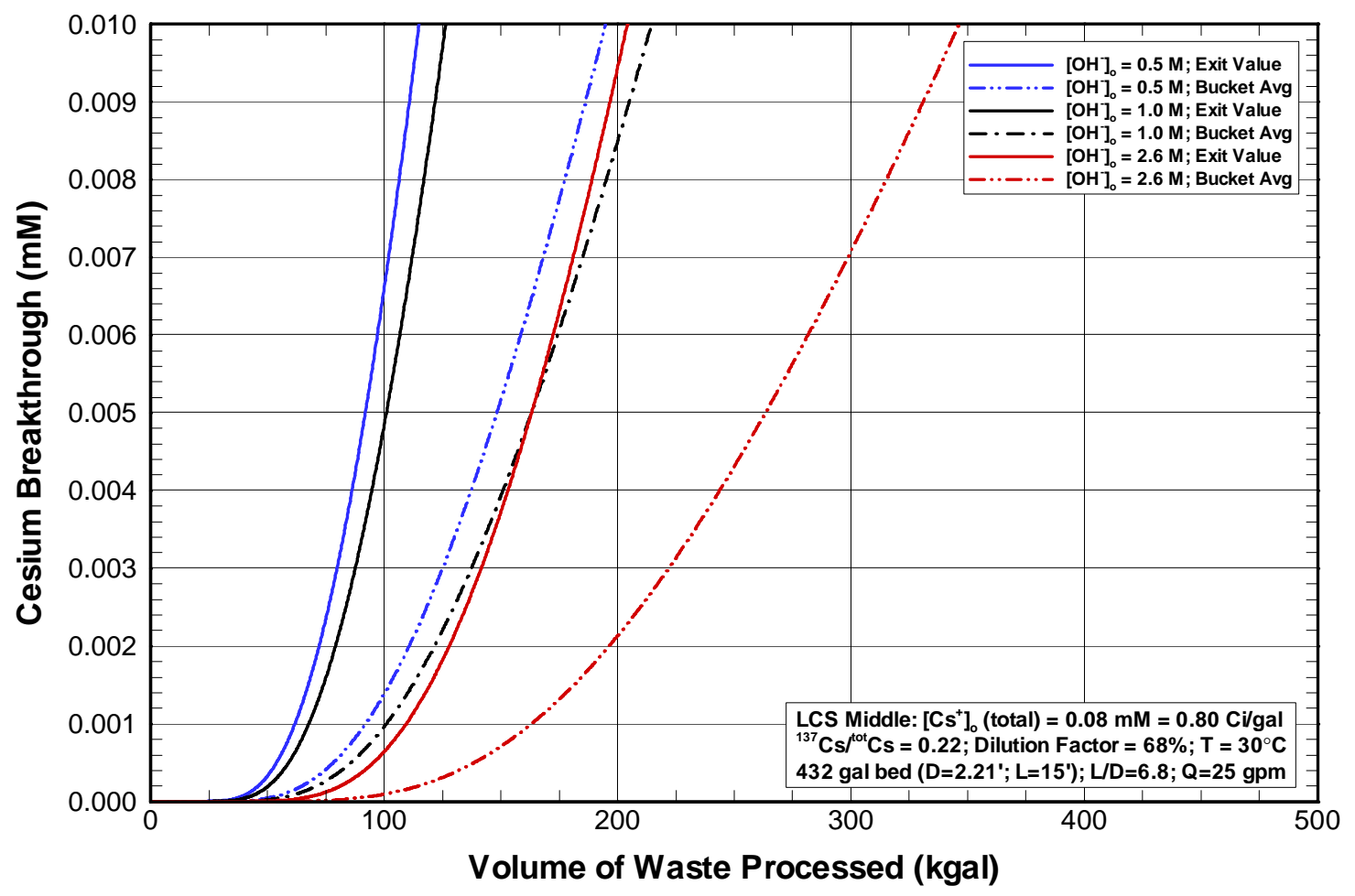

Figure 20. Cesium Breakthrough Curves for LCS Middle Salt Solution with Hydroxide Concentrations of 0.5, 1.0 and 2.6 M.

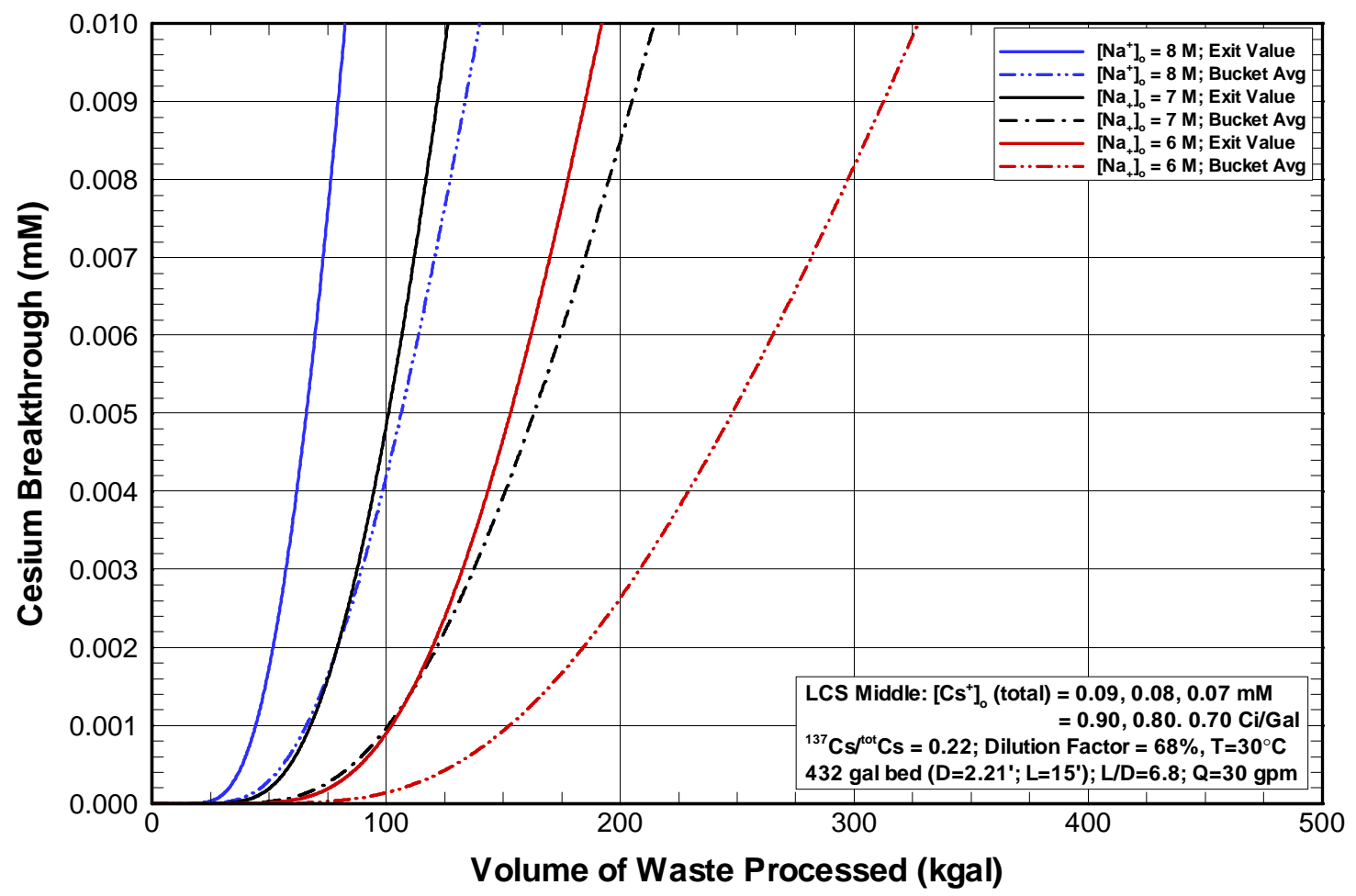

Figure 21. Cesium Breakthrough Curves for LCS Middle Waste Solution with Dilution to a Sodium Concentration of $6 \mathrm{M}$ and Concentration to $8 \mathrm{M}$. 
Figure 22 shows breakthrough curves for a variety of column sizes and length-to-diameter (L/D) ratios. Each graph shows the breakthrough for a particular column configuration (i.e., size and dimensions) when fed LCS Middle waste solution with a cesium concentration of $0.08 \mathrm{mM}$. The waste volume processed can be determined for any decontamination factor desired. For example, assuming a bucket average limit of $0.08 \mathrm{Ci} /$ gal, requires a decontamination factor (DF) of 10, and a cesium concentration of $0.008 \mathrm{mM}$. For this condition, Figure 22 shows that a 288, 296, 432 gal column processes 107,000, 112,000 and 195,000 gallons of waste, respectively.

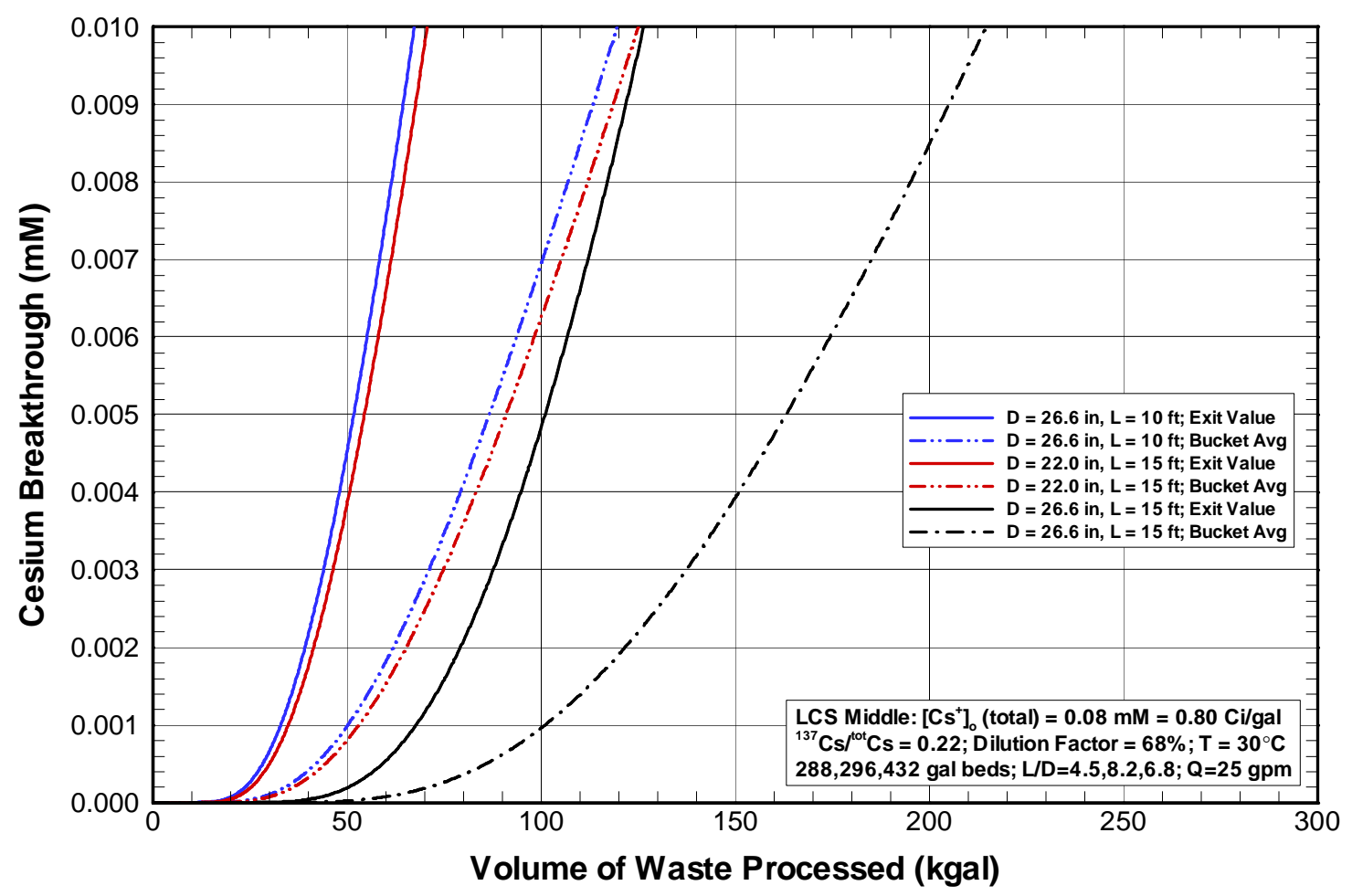

Figure 22. Cesium Breakthrough Curves for LCS Middle Salt Solution with Three Different IX Column Designs. 


\subsection{Cesium Column Inventory Analysis for IE-910 and IE-911}

The average Cs-137 column loading and the axial Cs-137 loading profile was computed for IE911 and IE-910 at the point where the bucket average cesium breakthrough met the criterion of $0.08 \mathrm{Ci} / \mathrm{gal}(0.008 \mathrm{mM})$. The average Cs-137 loadings for the various tank feed solutions are summarized in Table 7. The axial Cs-137 loading profiles for IE-911 and IE-910 are shown in Figures 23 to 34 for the breakthrough curves in Section 7. The axial cesium loading was computed from the corresponding axial aqueous cesium concentration using the appropriate algebraic isotherm. The axial Cs-137 loading was computed from the axial cesium loading using a CST bulk density of $1.0 \mathrm{~g} / \mathrm{ml}$, specific activity of Cs-137 (87 Ci/g) and assuming the Cs-137 comprises 22 mole $\%$ of the total cesium.

Table 7. Average Cs-137 Loading for Various Tank Feed Solutions.

\begin{tabular}{|c|c|c|c|c|c|c|c|}
\hline $\begin{array}{c}\text { Scenario } \\
\text { No. }\end{array}$ & Figure & $\begin{array}{c}\text { Tank } \\
\text { Feed }\end{array}$ & $\begin{array}{c}\text { Composition } \\
\text { Variability }\end{array}$ & $\begin{array}{c}\text { Feed } \\
\text { Flow } \\
(\mathbf{g p m})\end{array}$ & $\begin{array}{c}\text { Feed } \\
\text { Temp } \\
(\mathbf{C})\end{array}$ & $\begin{array}{c}\text { Cs-137 } \\
\text { Loading } \\
\text { IE-911 } \\
(\mathbf{C i} / \mathbf{L})\end{array}$ & $\begin{array}{c}\text { Cs-137 } \\
\text { Loading } \\
\text { IE-910 } \\
(\mathbf{C i} / \mathbf{L})\end{array}$ \\
\hline \hline 1 & 23 & LCS Early & Nominal & 25 & 30 & 118 & 173 \\
\hline 2 & 24 & LCS Middle & Nominal & 25 & 30 & 98 & 145 \\
\hline 3 & 25 & LCS Late & Nominal & 25 & 30 & 426 & 627 \\
\hline 4 & 26 & LCS Average & Nominal & 25 & 30 & 66 & 96 \\
\hline 5 & 27 & Tank 41H & Nominal & 25 & 30 & 38 & 56 \\
\hline 6 & 28 & LCS Middle & Nominal & 8 & 30 & 118 & 173 \\
\hline 7 & 28 & LCS Middle & Nominal & 20 & 30 & 103 & 151 \\
\hline 8 & 28 & LCS Middle & Nominal & 30 & 30 & 95 & 140 \\
\hline 9 & 28 & LCS Middle & Nominal & 40 & 30 & 90 & 133 \\
\hline 10 & 29 & LCS Middle & Nominal & 25 & 15 & 146 & 215 \\
\hline 11 & 29 & LCS Middle & Nominal & 25 & 40 & 76 & 112 \\
\hline 12 & 30 & LCS Middle & Low Cs+ & 25 & 30 & 34 & 50 \\
\hline 13 & 30 & LCS Middle & High Cs+ & 25 & 30 & 187 & 275 \\
\hline 14 & 31 & LCS Middle & Low K+ & 25 & 30 & 100 & 147 \\
\hline 15 & 31 & LCS Middle & High K+ & 25 & 30 & 96 & 142 \\
\hline 16 & 32 & LCS Middle & Low OH- & 25 & 30 & 89 & 131 \\
\hline 17 & 32 & LCS Middle & High OH- & 25 & 30 & 160 & 236 \\
\hline 18 & 33 & LCS Middle & Low Na+ & 25 & 30 & 123 & 181 \\
\hline 19 & 33 & LCS Middle & High Na+ & 25 & 30 & 77 & 113 \\
\hline
\end{tabular}


Small Column Ion Exchange Analysis for Removal of Cesium from SRS Revision (Date):

$0(12 / 03)$

Low Curie Salt Solution Using Crystalline Silicotitanate (CST) Resin

\begin{tabular}{|c|c|c|c|c|c|c|c|}
\hline $\begin{array}{c}\text { Scenario } \\
\text { No. }\end{array}$ & Figure & Tank & Composition & Feed & Feed & $\begin{array}{c}\text { Cs-137 } \\
\text { Loading } \\
\text { IE-911 } \\
\text { Femp }\end{array}$ & $\begin{array}{c}\text { Cs-137 } \\
\text { Loading } \\
\text { IE-910 } \\
(\mathbf{C i} / \mathbf{L})\end{array}$ \\
\hline 20 & 34 & LCS Middle & Nominal & 25 & 30 & 92 & 135 \\
\hline 21 & 34 & LCS Middle & Nominal & 25 & 30 & 91 & 134 \\
\hline
\end{tabular}




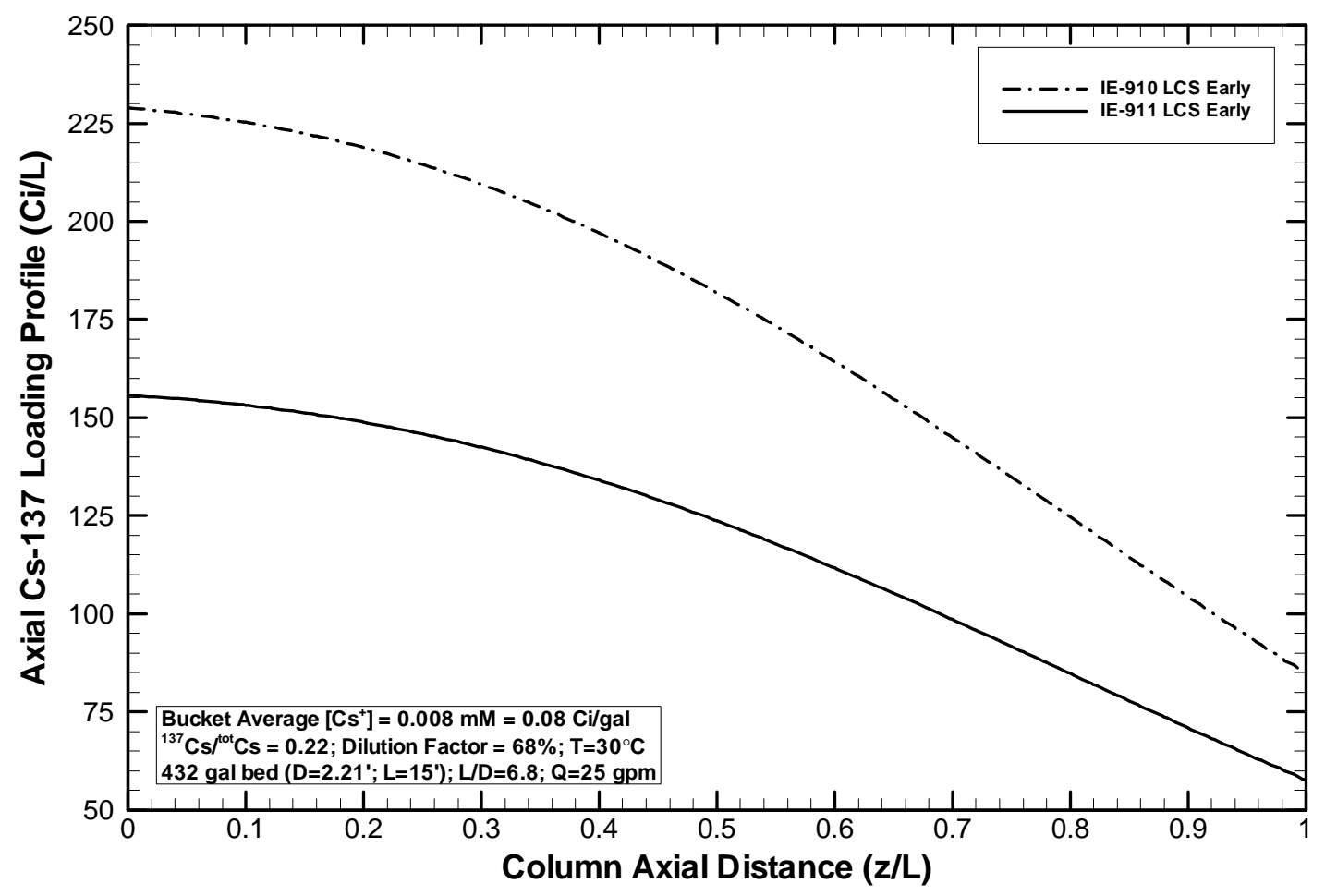

Figure 23. CST Axial Cs-137 Loading Profile for LCS Early Waste Solution at a Bucket Average Criterion of $0.08 \mathrm{Ci} / \mathrm{gal}$.

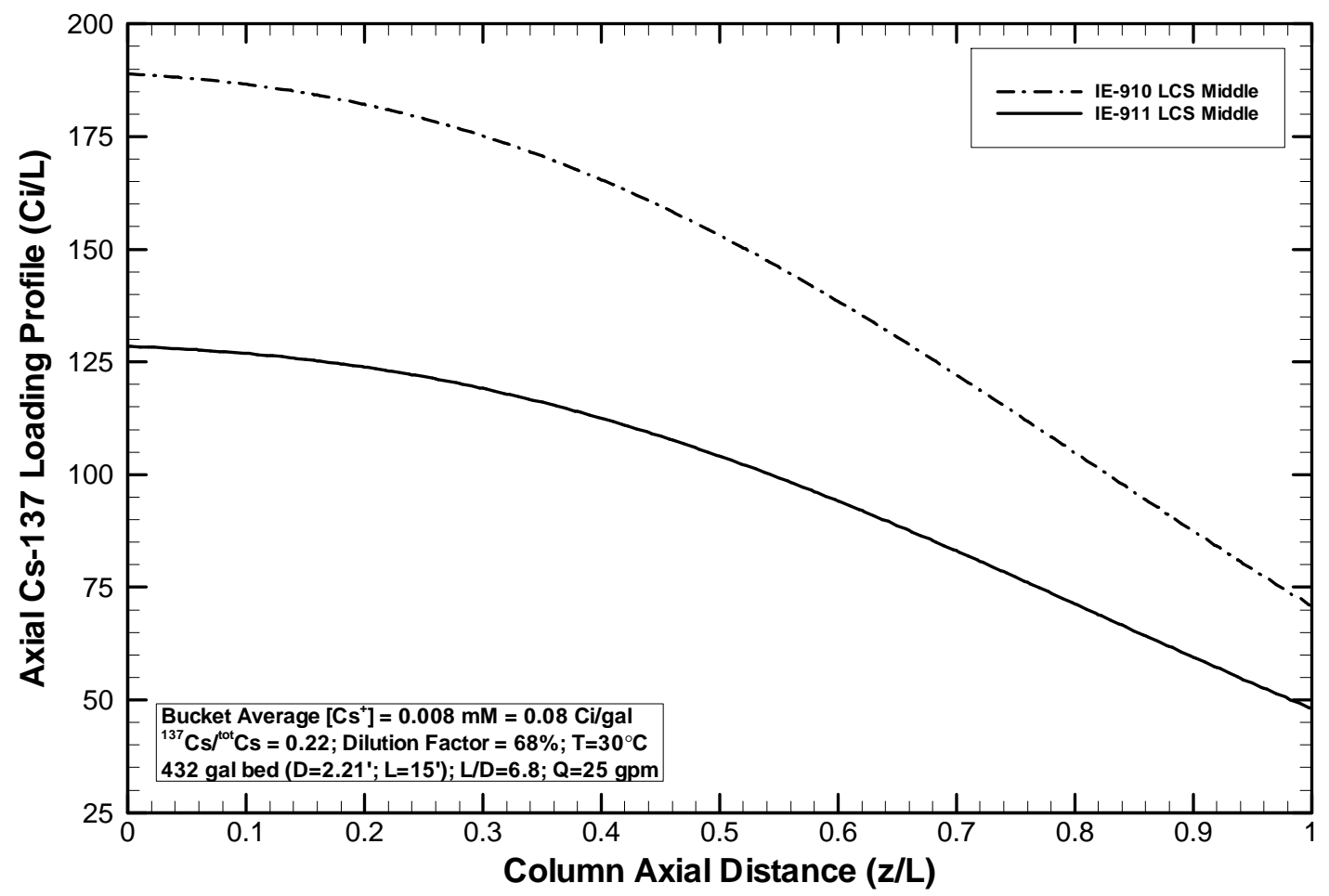

Figure 24. CST Axial Cs-137 Loading Profile for LCS Middle Waste Solution at a Bucket Average Criterion of $0.08 \mathrm{Ci} / \mathrm{gal}$. 


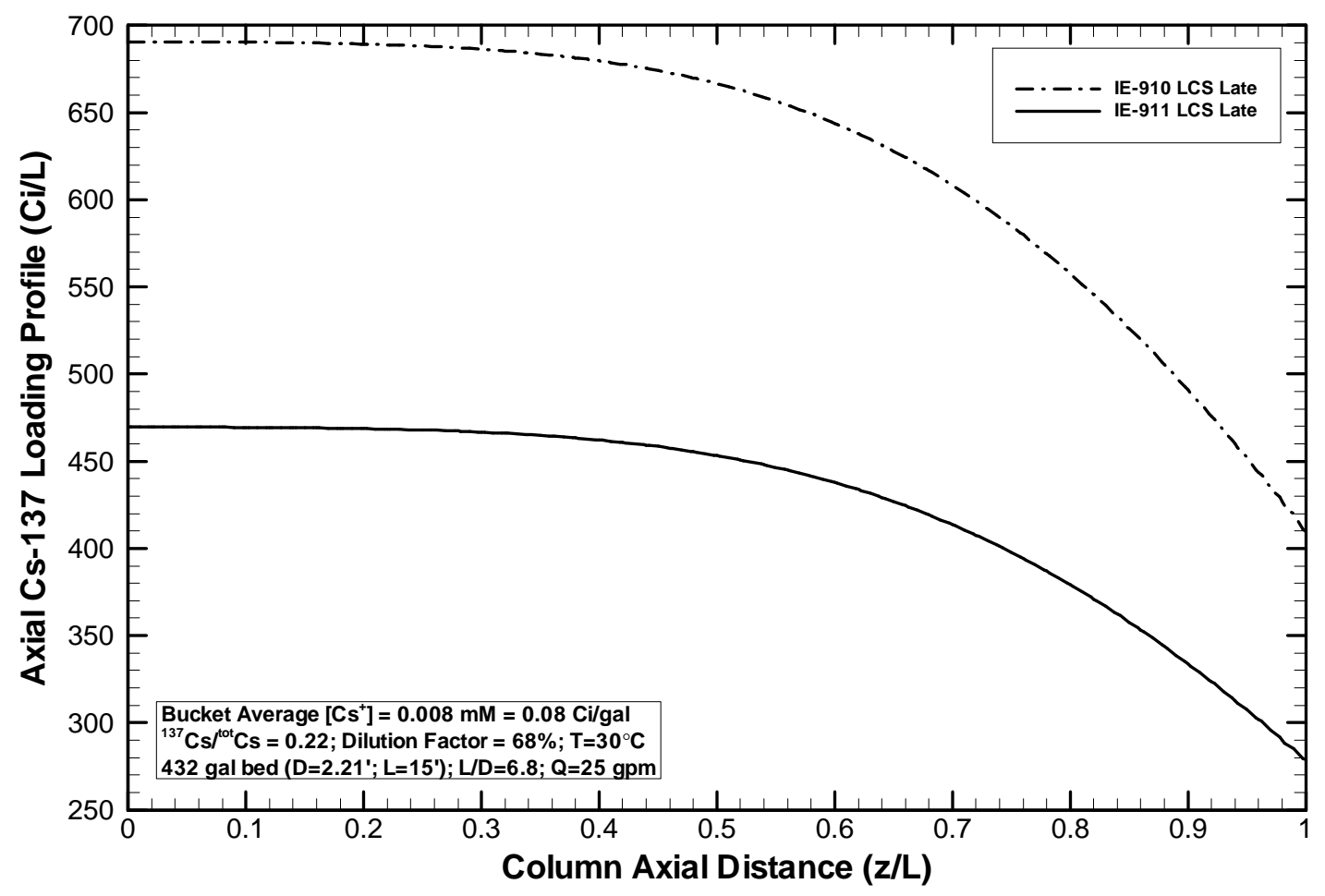

Figure 25. CST Axial Cs-137 Loading Profile for LCS Late Waste Solution at a Bucket Average Criterion of $0.08 \mathrm{Ci} / \mathrm{gal}$.

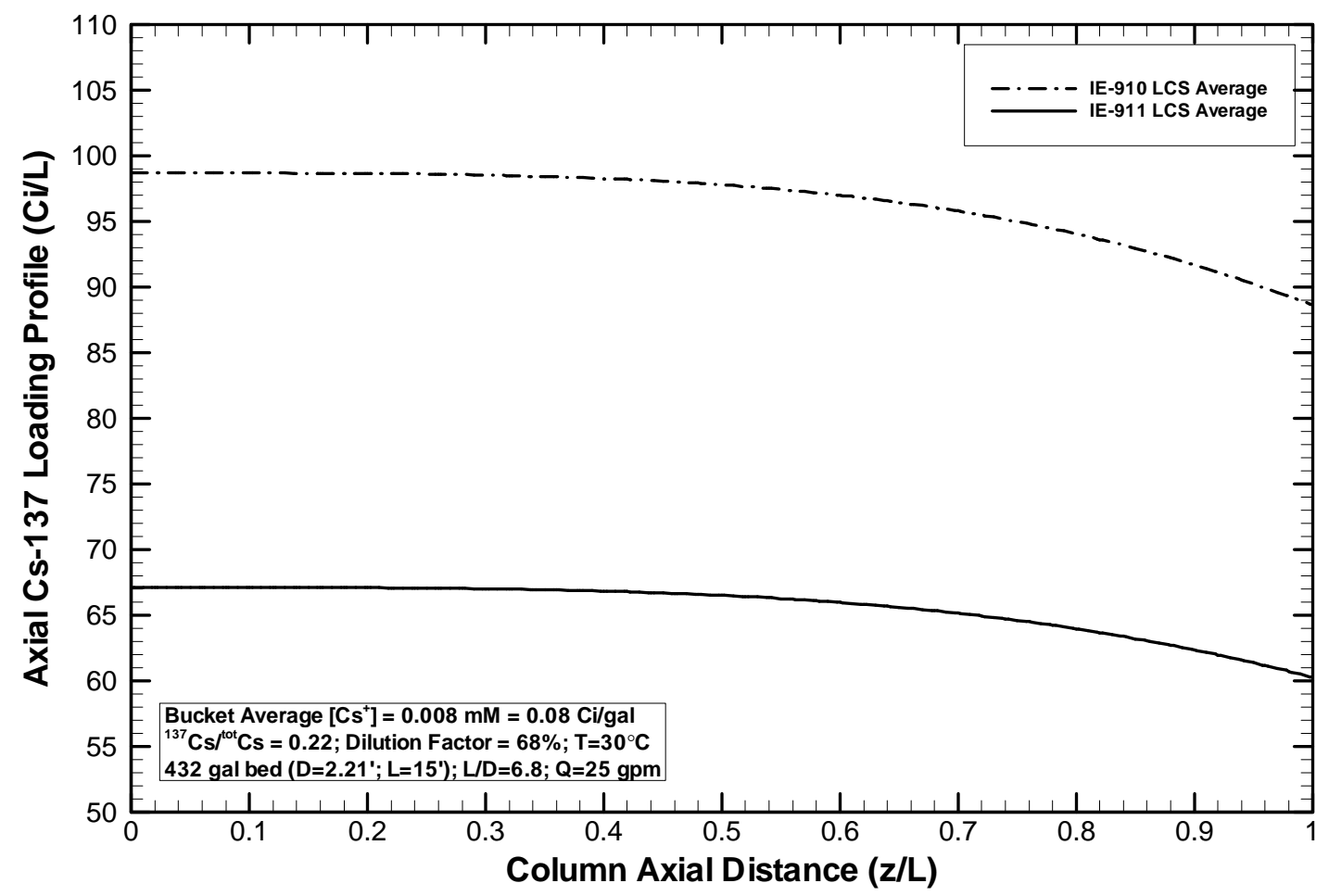

Figure 26. CST Axial Cs-137 Loading Profile for LCS Average Waste Solution at a Bucket Average Criterion of $0.08 \mathrm{Ci} / \mathrm{gal}$. 


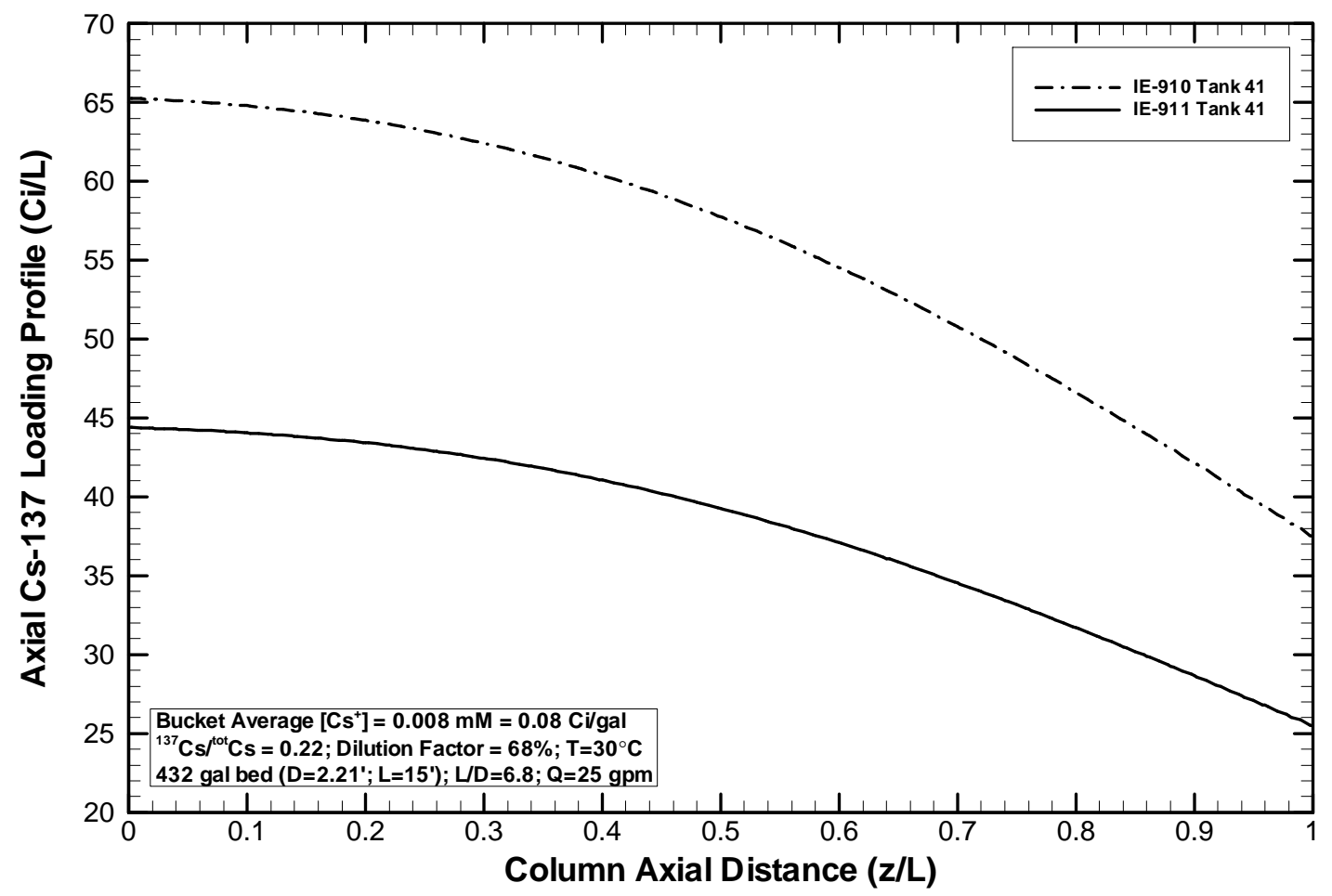

Figure 27. CST Axial Cs-137 Loading Profile for Recent Tank 41H Dissolved Salt Solution at a Bucket Average Criterion of $0.08 \mathrm{Ci} / \mathrm{gal}$.

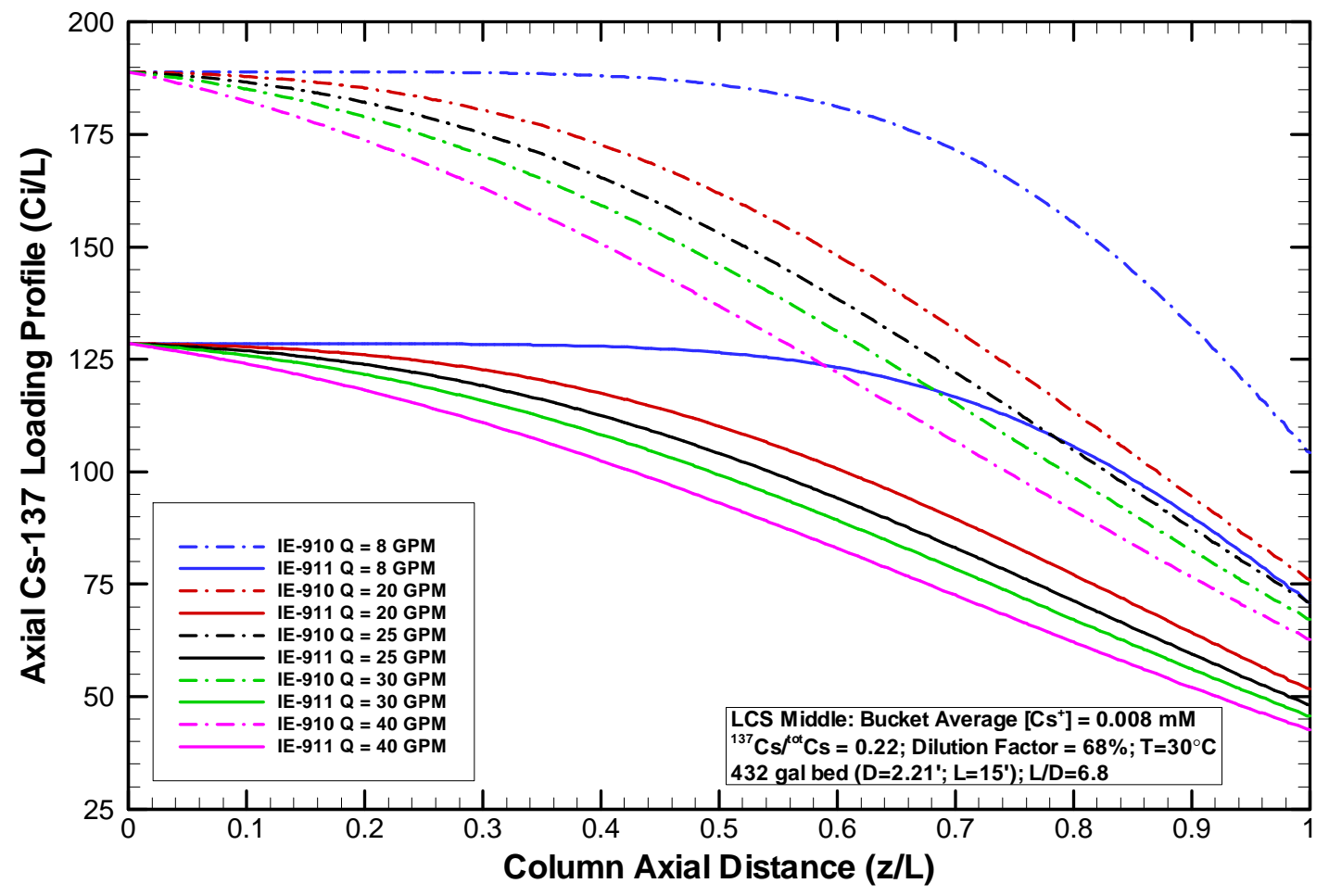

Figure 28. CST Axial Cs-137 Loading Profile for LCS Middle Waste Solution Flowing at $8,20,25,30$ and $40 \mathrm{gpm}$. 


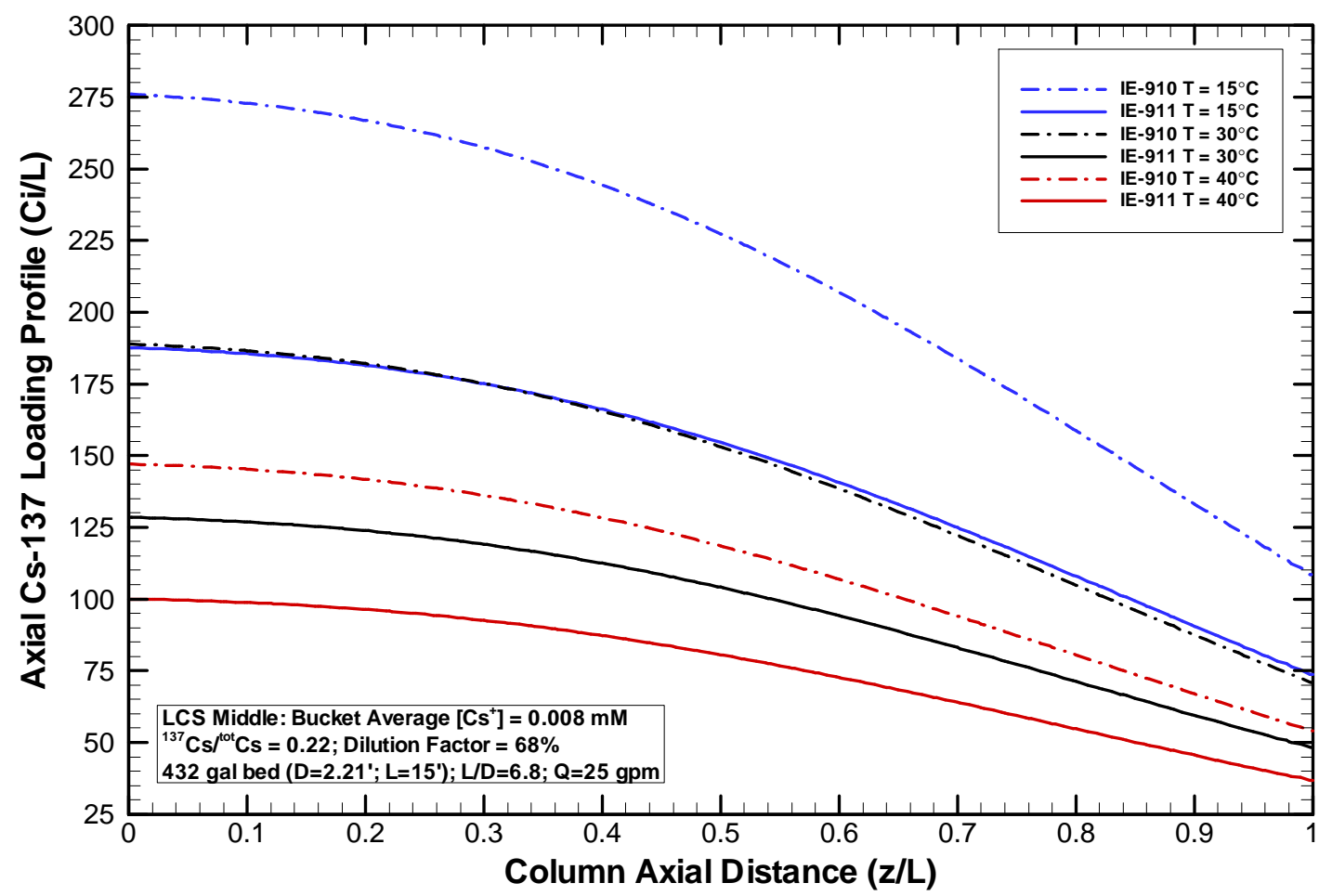

Figure 29. CST Axial Cs-137 Loading Profile for LCS Middle Waste Solution at 15, 30 and $40{ }^{\circ} \mathrm{C}$.

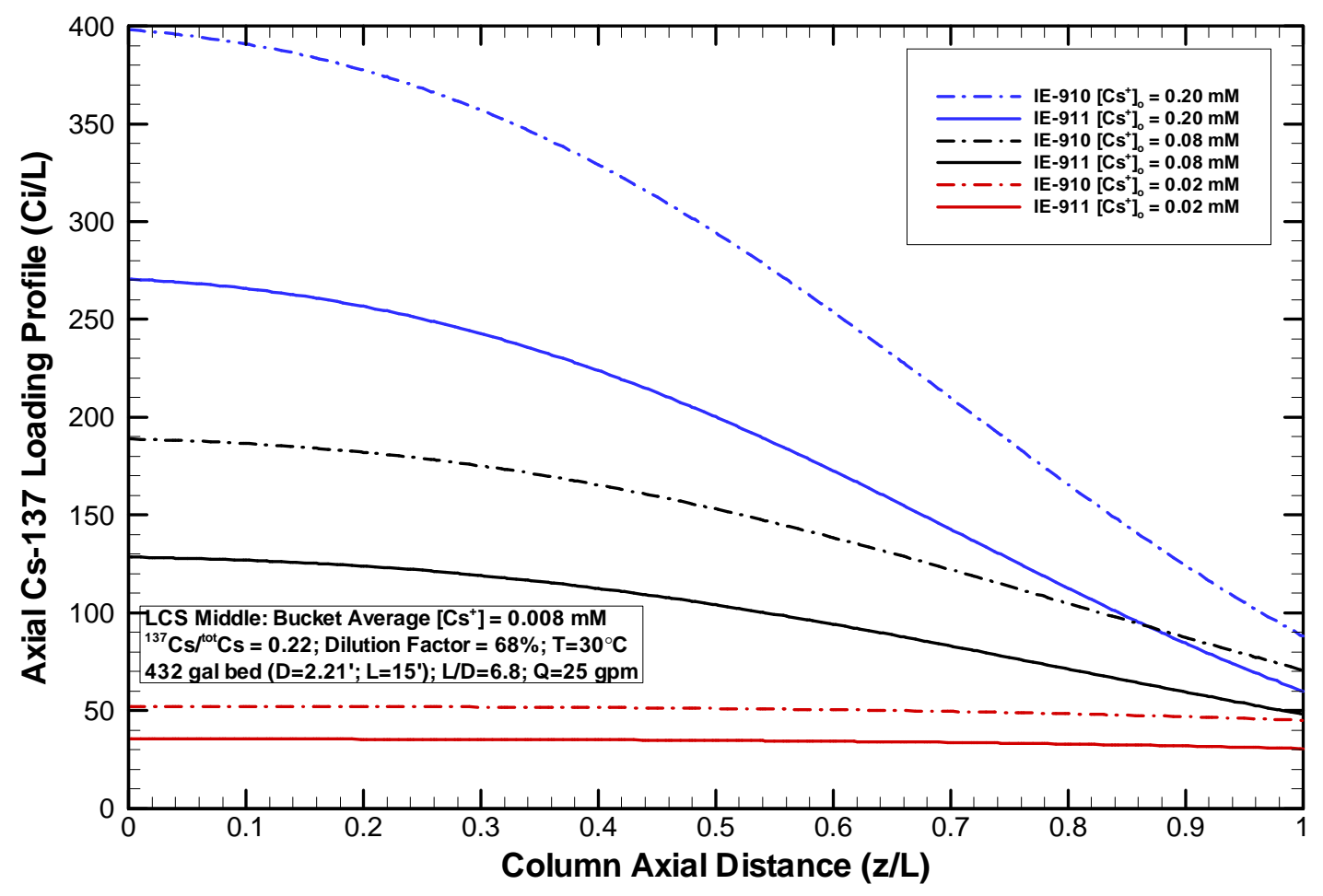

Figure 30. CST Axial Cs-137 Loading Profile for LCS Middle Waste Solution at Cesium Concentrations of $0.20,0.08$ and $0.02 \mathrm{mM}$. 


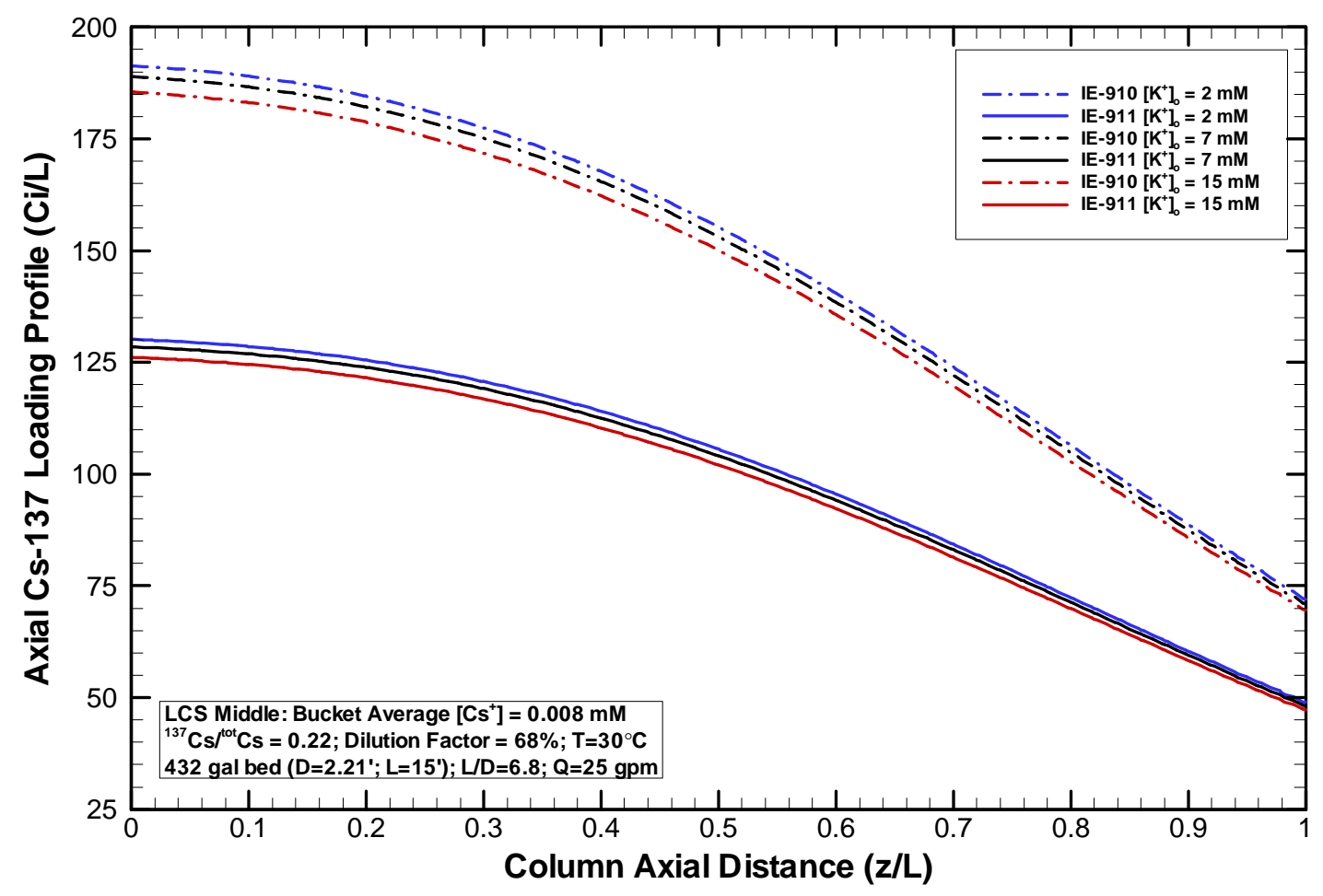

Figure 31. CST Axial Cs-137 Loading Profile for LCS Middle Waste Solution at Potassium Concentrations of 2, 7 and $15 \mathrm{mM}$.

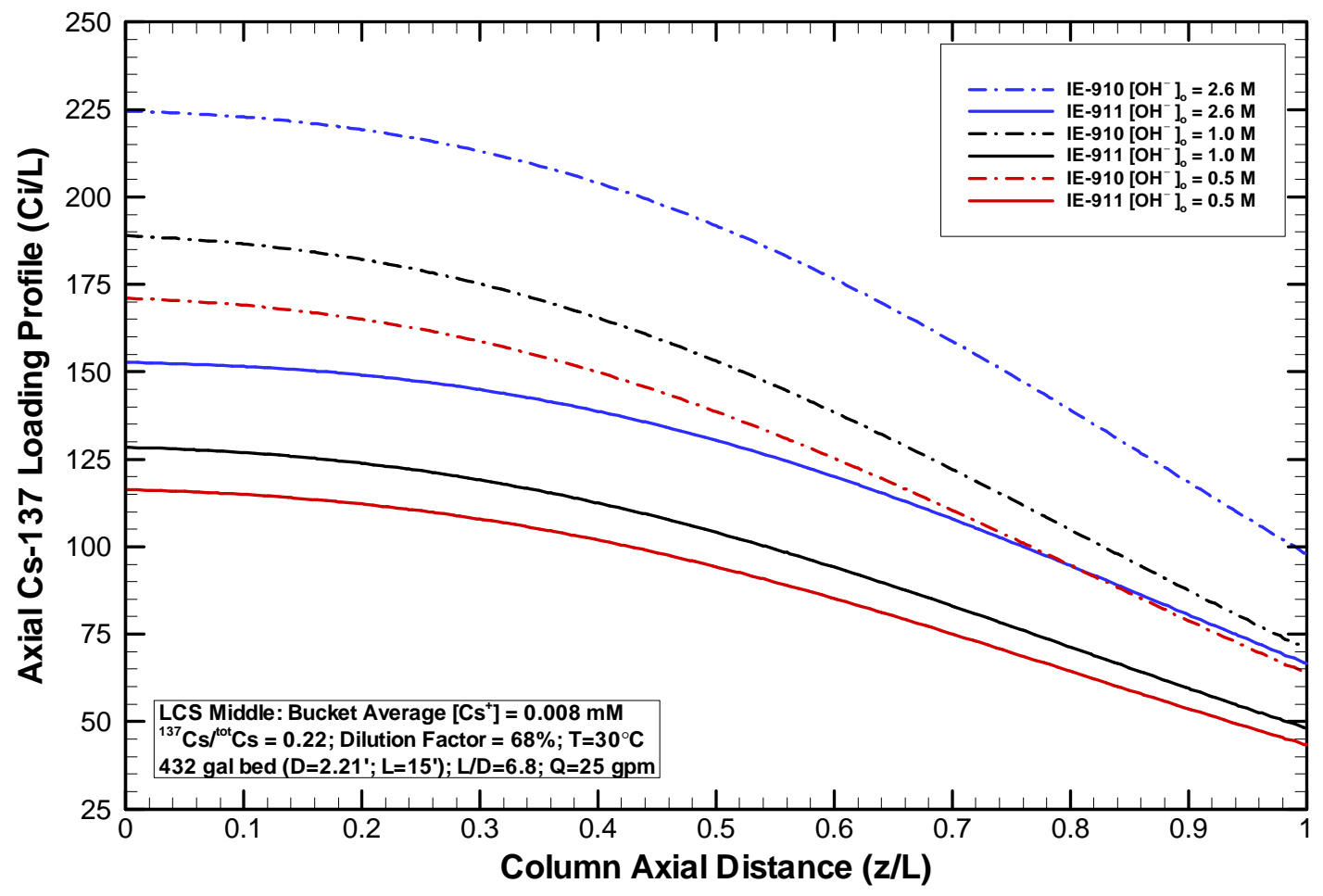

Figure 32. CST Axial Cs-137 Loading Profile for LCS Middle Waste Solution at Hydroxide Concentrations of 2.6, 1.0 and 0.5 M. 


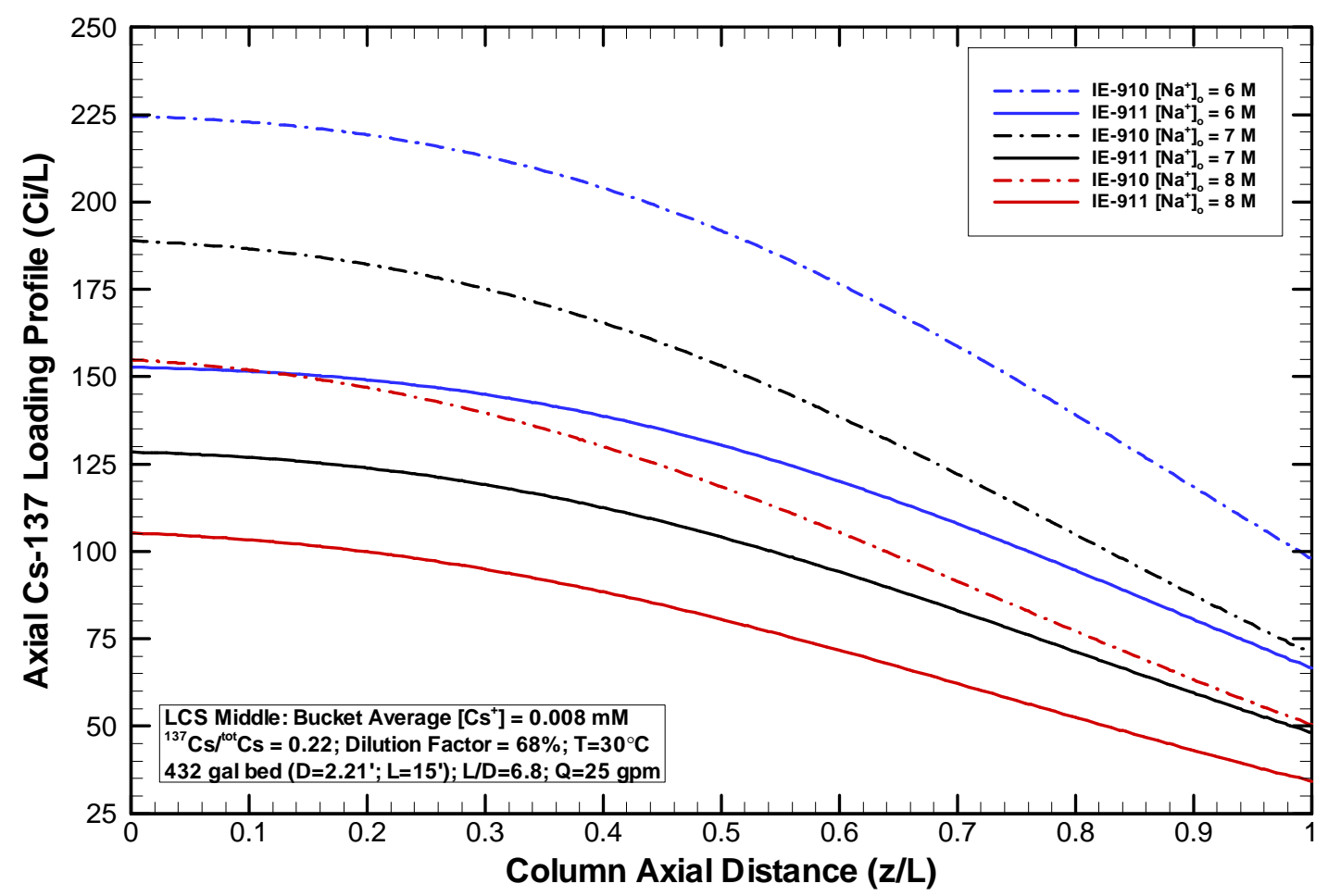

Figure 33. CST Axial Cs-137 Loading Profile for LCS Middle Waste Solution at Sodium Concentrations of 6, 7 and $8 \mathrm{M}$ (Dilution and Concentration).

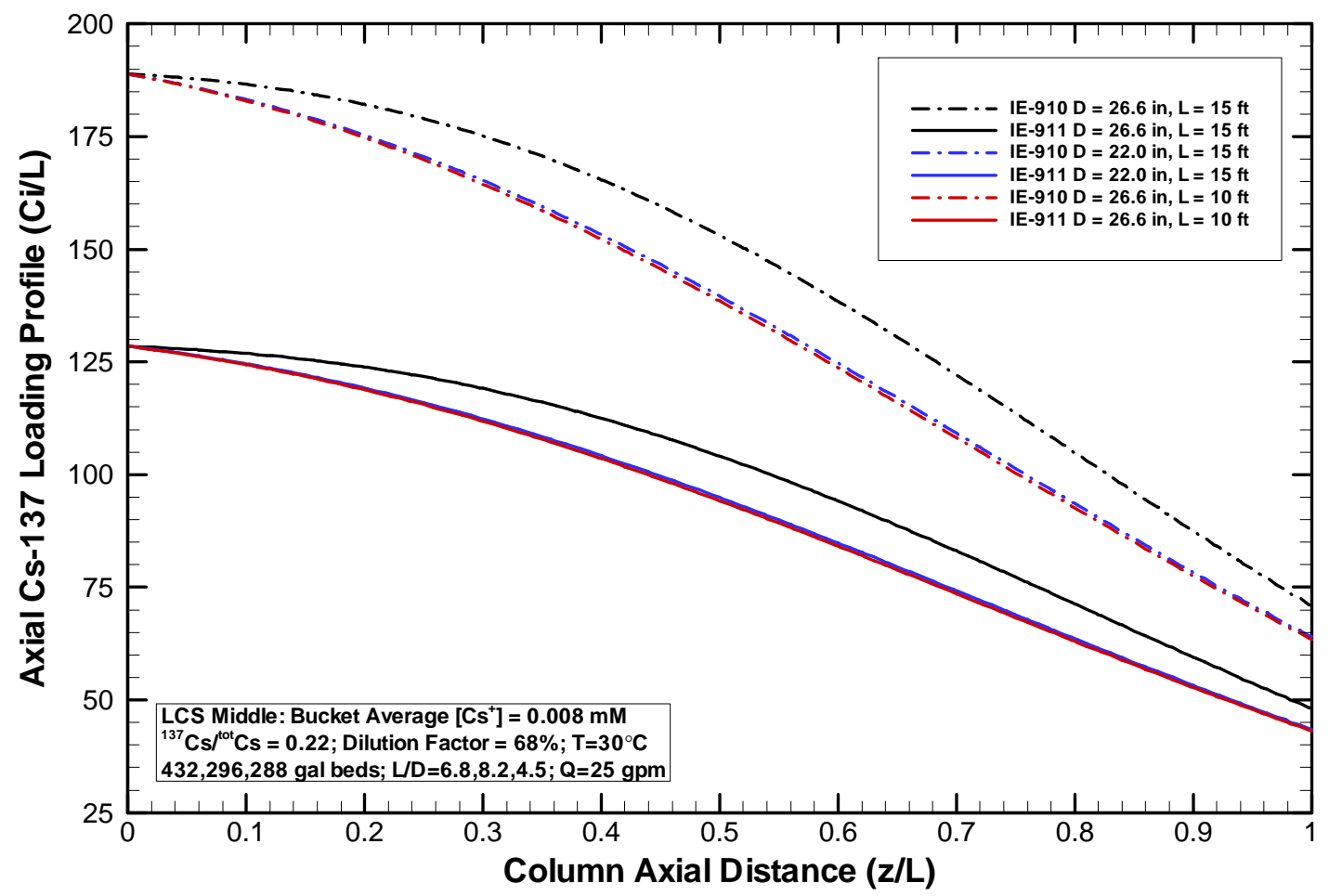

Figure 34. CST Axial Cs-137 Loading Profile for LCS Middle Waste Solution with Three Different IX Column Designs. 


\subsection{Conclusions}

Savannah River Technology Center (SRTC) researchers modeled ion exchange removal of cesium from dissolved salt waste solutions. The results assist in evaluating proposed configurations for an ion exchange process to remove residual cesium from low curie waste streams. A process for polishing (i.e., removing small amounts) of cesium may prove useful should supernate draining fail to meet the Low Curie Salt (LCS) target limit of $0.1 \mathrm{Ci}$ of Cs-137 per gallon of salt solution. Cesium loading isotherms and column breakthrough curves for Low Curie dissolved salt solutions were computed to provide performance predictions for various column designs. Performance calculations generated the following results and conclusions.

- Performance modeling supported the design effort that culminated in the selection of a 432gal column, 28 inches diameter and 15 feet long.

A 432-gal column balances concerns about column heating and the operating cycle (i.e., the time between column change outs). The column packing must be changed after 2 to 17 days of operation at $25 \mathrm{gpm}$.

- The ion exchange column will process a variety of waste compositions.

Four waste compositions reflecting potential variation in dissolved salt cake wastes and Tank $41 \mathrm{H}$ were examined.

Modeling results indicate that a 432-gallon column can process between 76,000 and 591,000 gallons of waste at an instantaneous cesium breakthrough of $0.08 \mathrm{Ci} / \mathrm{gal}$.

Modeling results indicate that a 432-gallon column can process between 127,000 and 905,000 gallons of waste at a bucket average cesium breakthrough of $0.08 \mathrm{Ci} / \mathrm{gal}$.

Cs-137 loadings on the 432 gallon CST columns range between 34 and $627 \mathrm{Ci} / \mathrm{L}$ at a bucket average cesium breakthrough of $0.008 \mathrm{mM}$.

- Modeling quantified the impacts of variations in concentrations of important waste components.

Increasing the initial cesium concentration reduces the volume that can be processed. A 10fold increase in initial cesium concentration $(0.02$ to $0.20 \mathrm{mM})$ greatly reduces the volume processed. For example, at the bucket average cesium breakthrough of $0.08 \mathrm{Ci} / \mathrm{gal}$, the reduction is $71 \%(458,000$ gal vs. 131,000 gal $)$.

Dilution and concentration of the LCS Middle salt solution to $6 \mathrm{M}$ and $8 \mathrm{M}$ sodium concentrations, respectively, decreases the volume of waste processed from 297,000 to 127,000 gallons.

Variation of potassium concentrations over the range expected in the LCS Middle salt solution has a minimal impact on the volume of waste processed ( \pm 2000 gals $)$. 
Increasing the concentration of hydroxide improves the volume of waste that can be processed per column loading. For the LCS Middle salt solution at a bucket average cesium breakthrough of $0.08 \mathrm{Ci} / \mathrm{gal}$, the volume of waste processed for hydroxide concentrations of $0.5 \mathrm{M}, 1.0 \mathrm{M}$ and $2.6 \mathrm{M}$ is $177,000,195,000$ and 315,000 gallons, respectively

- Modeling showed the effects of changes in several processing parameters allowing for selection of optimal process conditions.

Decreasing the flow rate from 40 to $8 \mathrm{gpm}$, increases the amount of waste that a $432 \mathrm{gal}$ column can process from 89,000 to 180,000 gallons.

Decreasing the liquid temperature from 40 to $15^{\circ} \mathrm{C}$, increases the amount of waste that a 432 gal column can process from 91,000 to 173,000 gallons.

Lowering decontamination factor increases the amount of waste that a column can process. 


\subsection{References}

Dimenna, R. A., et al., 2001. "Bases, Assumptions, and Results of the Flowsheet Calculations for the Decision Phase Salt Disposition Alternatives," WSRC-RP-99-00006, Rev. 3, May 2001.

Hamm, L. L., Smith III, F. G., and M. A. Shadday, 1999. “QA Verification Package for VERSELC Version 7.80," WSRC-TR-99-00238, 1999.

Hamm, L. L., Hang, T., McCabe, D. J. and W. D. King, 2002. "Preliminary Ion Exchange Modeling for Removal of Cesium from Hanford Waste Using Hydrous Crystalline Silicotitanate Material," WSRC-TR-2001-00400, July 2002.

Hamm, L. L., and D. D. Walker, 2003. "VERSE-LC Modeling of Ion Exchange Column Performance for Low Curie Salt," WSRC-TR-2003-00243, Rev 0, July 16, 2003.

Martino, C. J., Wilmarth, W. R., Diprete, D. P., and C. C. Diprete, 2003. "Tank41H Dissolved Saltcake Sample (HTF-E-03-91-92) Saltstone Waste Acceptance Criteria Analysis," WSRCTR-2003-00380, Rev. 0, August 28, 2003.

Oak Ridge National Laboratory, 1995. "Integraded Data Base Report - 1994: U.S. Spent Nuclear Fuel and Radioactive Waste Inventories, Projections, and Characteristics," DOE/RW006, Rev. 11, September 1995.

Taylor, P. A., Jennings, H. L., and J. F. Walker, Jr. 2003. "Letter Report - Clumping Behavior and Cesium Loading Results For Crystalline Silicotitanate and Zeolite in SRS Dissolved Salt Simulants," PER/ORNL/NTEL-IX-002, August 25, 2003.

Walker, D. D., 2003. "Simulant Compositions for Low Curie Salt Testing," WSRC-TR-200300244.

Whitley, R. D. and N.-H. Wang, 1998. “User's Manual VERSE (VErsatile Reaction Seperation) Simulation for Liquid Phase Adsorption and Chromatography Processes," School of Chemical Engineering, Purdue University, July, 1998.

Zheng, Z., Gu, D. and R. G. Anthony, 1996. "Estimation of Cesium Ion Exchange Distribution Coefficients for Concentrated Electrolytic Solutions When Using Crystalline Silicotitanates," Ind. Eng. Chem. Res. 1995, 34, 2142-2147.

Zheng, Z., Phillip, C. V., Anthony, R. G., Krumhansl, J. L., Trudell, D. E. and J. E. Miller. 1996a. "Ion Exchange of Group I Metals by Hydrous Crystalline Silicotitanates," Ind. Eng. Chem. Res. 1996, 35, 4246-4256. 